\title{
Comparative study between the prophylactics Effects of aqueous extract of Black Currant (Vitis vinferia.L) and vitamin $E$ on some biological parameters related with heart diseases in oxidative Stressed rats
}

\author{
Abdul-Katum, A. H. and Khudair, K.K. \\ Dept. Of physiology and Pharmacology- College of vet. Med. - Baghdad \\ University - Iraq
}

\begin{abstract}
Summary
This study was designed to investigate the prophylactic effect of aqueous extract of black currant concentrate on some biological markers related with heart disease in male rat treated $\mathrm{H} 2 \mathrm{O} 2$. It also aimed at comparing the prophylactic effect of black currant concentrate to that of vit $\mathrm{E}$.

Forty adult male rats were divided randomly into equal groups (ten rat/group) \& were treated as follows for 42 days. Rats in the first group (G I) were received normal water with oral intubation of sun flower oil $1 \mathrm{ml} / \mathrm{rat}$ and consider as control group. Animals of the second group (G $\Pi)$ were received $0.5 \% \mathrm{H} 2 \mathrm{O} 2$ in drinking water, while rats of the third group (G $W$ ) were received $0.5 \% \mathrm{H} 2 \mathrm{O} 2$ in drinking water with oral intubation of vit E $400 \mathrm{I} . \mathrm{U} / \mathrm{Kg}$.B.W diluting in sun flower oil for each rat daily. While animals in the fourth group (G IV) were intubated daily $60 \mathrm{mg} / \mathrm{kg}$ body weight of aqueous extract of black currant concentrate plus $0.5 \% \mathrm{H} 2 \mathrm{O} 2$ in drinking water.

Fasting blood samples were collected at 0,21 , and 42 days of experiment to study the following parameters:

A - Platelet count (PC) and prothrombin time (PT).

B- Serum concentration of total cholesterol TC, triacylglycerol TAG, High density lipoprotein-cholesterol HDL-C, Low density lipoprotein-cholesterol LDL-C and Very low density lipoprotein- cholesterol VLDL-C of each group were measured. These parameters were regarded as biomarkers of atherosclerosis and coronary heart disease (CHD). Furthermore section of heart $\&$ aorta were assessed for histopathogical studies.

The result revealed that administration of $0.5 \% \mathrm{H} 2 \mathrm{O} 2$ in drinking water for six weeks (42days) caused significant increase $(\mathrm{p}<0.05)$ in platelet count $\&$ in serum TC,TAG,LDL-C, and VLDL-C concentration with significant decrease $(\mathrm{p}<0.05)$ in prothrombin time and HDL-C concentration as compared to other groups, on other hand oral intubation of vitamin $\mathrm{E}$ or aqueous extract of black currant concentrate in addition to $\mathrm{H} 2 \mathrm{O} 2$ (groups $\amalg$ and IV respectively) decreased the serum concentration of TC, TAG, LDL-C, VLDL-C, and platelet count
\end{abstract}


comparing to $\mathrm{H} 2 \mathrm{O} 2$ treated group \& the control. Besides, the black currant concentrate and vitamin E caused significant elevation in serum HDL-C concentration \& prothrombin time.

Histological study revealed that $0.5 \% \mathrm{H} 2 \mathrm{O} 2$ intubation initiated aortic atheromatus lesions characterized by collagen proliferation, thickness of the intima, infiltration of inflammatory cells\& focal foamy cell in subintimal layer with narrowing of the blood vessels. While histological section of aorta\& heart of $\mathrm{H} 2 \mathrm{O} 2$ plus black currant concentrate showed complete regression of atheromatus lesions caused by $\mathrm{H} 2 \mathrm{O} 2$ intubation.

It seems that black currant concentrate exert protective actions against $\mathrm{H} 2 \mathrm{O} 2$ induced oxidative stress, atherosclerosis \& change in some biological Markers related to heart disease. Such effects were more effective than vitamin $\mathrm{E}$ in some parameters.

According to the available literature it seems that this is the first study showed the antiatherosclerotic properties of aqueous extract of black currant concentrate \& it's more potent than vitamin $\mathrm{E}$ in this issue. 
دراسة مقارنة بين التأثير الوقائي للمستخلص المائي لمركز الزبيب الأسود

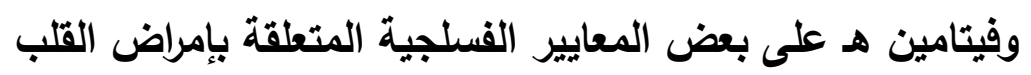

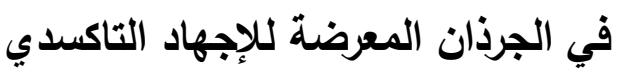

\author{
خالصة كاظم خضير - عامر حسن عبد الكاظم \\ فرع الفسلجة والأدوية - كلبة الطب البيطري -جامعة بغداد - العراق
}

\title{
الخلاصة
}

صمدت هذه الدراسة لمعرفة التأثير الوقائي لمركز الزبيب الأسود في بعض المعايير الحيوية

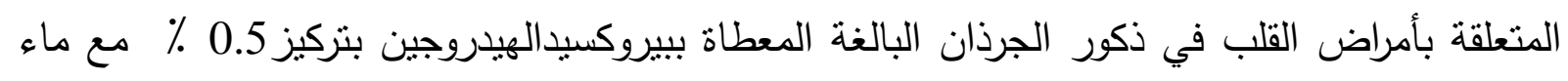

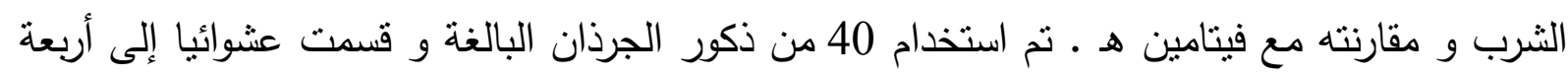

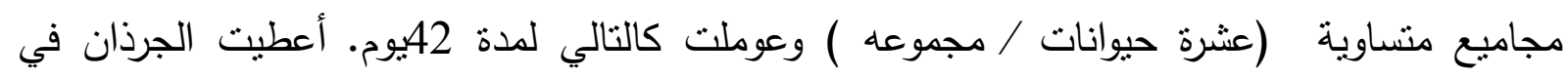

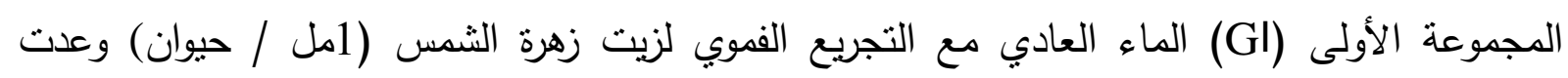

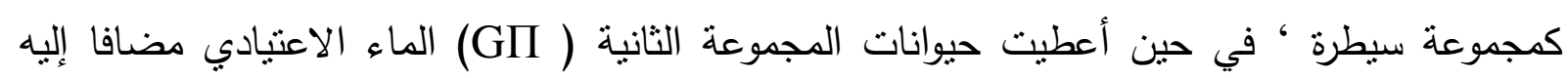

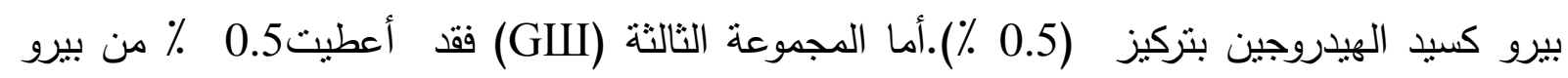

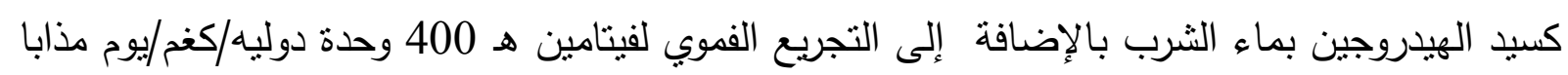

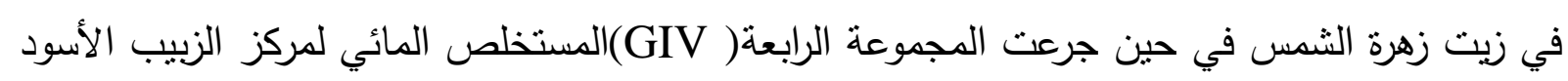

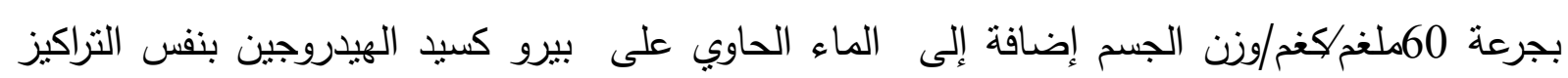

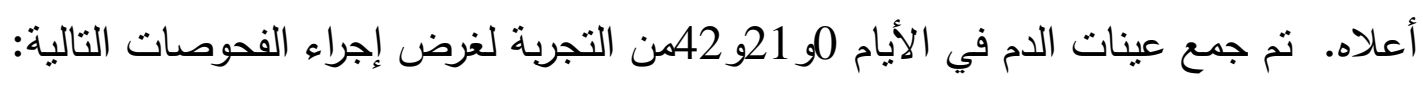

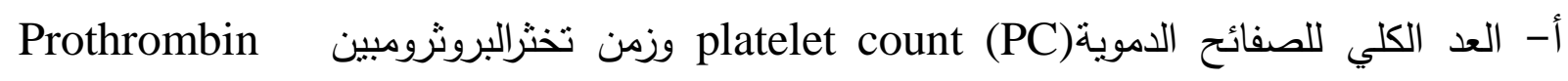
- time(PT)

ب- فحوصات المصل وشملت قياس نركيز الكوليستيرول الكلي TC وقياس تركيزكلسيرول ثلاثي

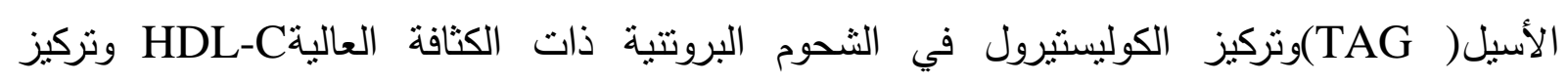

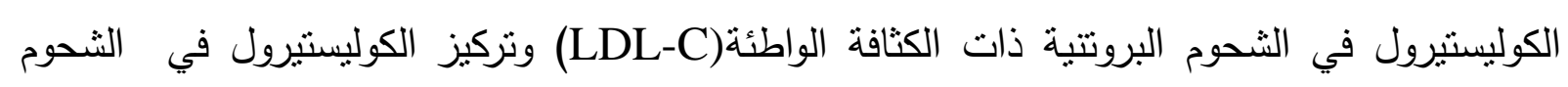

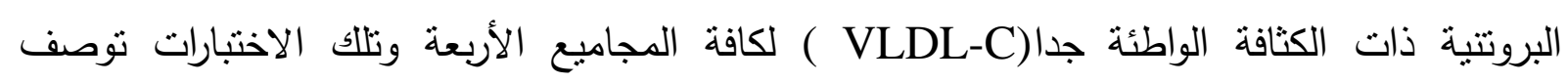
كمقييس لتصلب الثرايين العصيدي وأمراض القلب الوعائية CHD. بالاضافه إلى اخذ مقاطع نسجيه الأليه

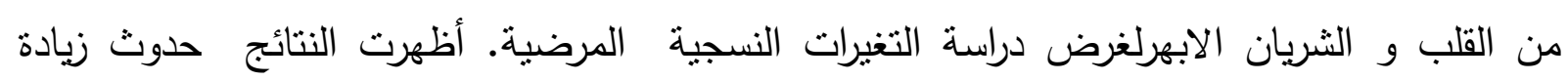

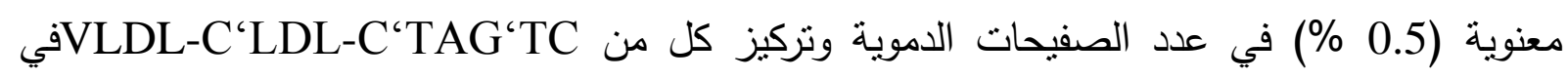




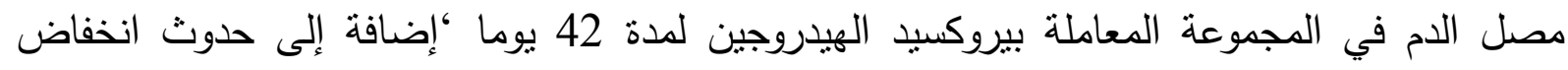

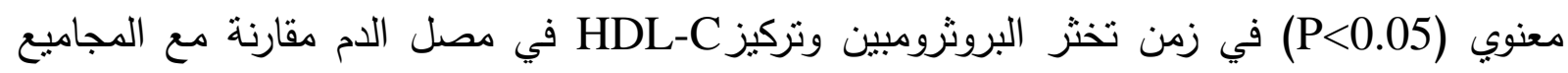

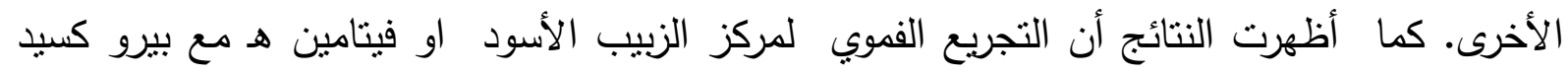

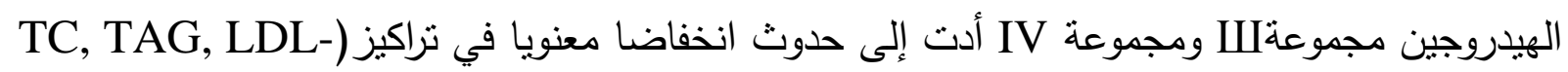
(C, VLDL-C

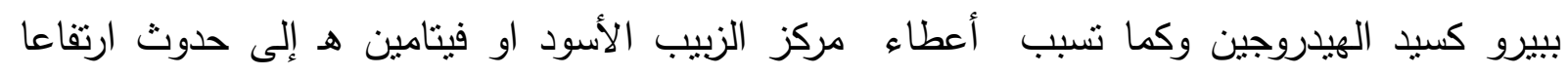

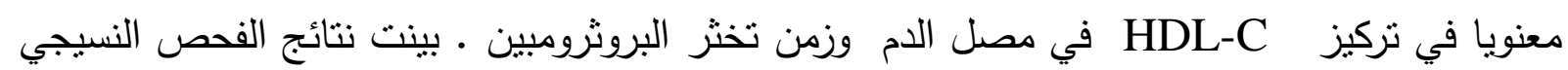
حدوث الآفات الأولية للتصلب العصيدي في ابهر الجرذان المعاملة ببيروكسيدالهيدروجين والتي تتميز بكثرة الكولاجين وزيادة سمك الطبقة الحشوية و ارتثاح الخلايا الالتهابية ووجود الخلايا الدهنية الموقعية

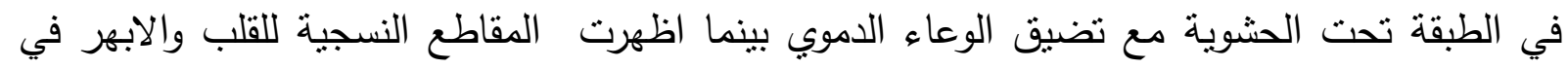
المجموعة المعاملة بـ0.5\% من بيرو كسيد الهيدروجين و مركز الزبيب الأسود انكفاء كلي لآفات التصلب العصيدي الذب سببه بيرو كسيد الهيدروجين. يبدو من نتائج هذه الدراسة التأثير الوقائي لمركز

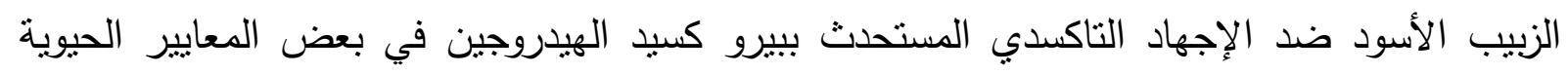

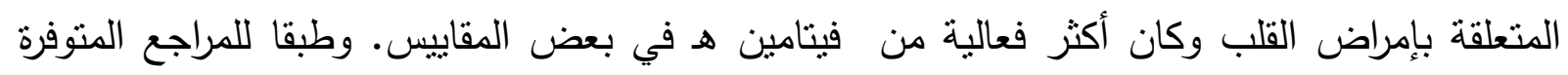

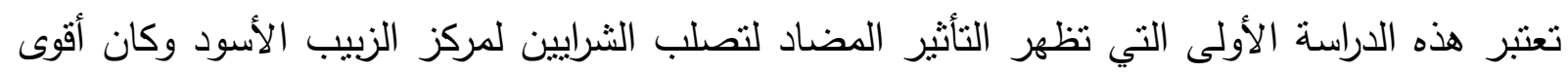
مقارنة بفيتامين هـ في هذا المجال.

\section{Introduction}

The medicinal and nutritional value of grapes (Vitis vinefera) has been heralded for thousands of years .Egyptians consumed this fruit at least 6,000 years ago. The round, ripe, sweat grape, were used to treat arrange of health problems including cancer, cholera, small pox, nausea, eye infection\& kidney\& liver diseases (1). The word currant is derived from the ancient Greek city, Corinth, and was first used to describe small dried grapes from that region (2). These grapes are know referred to and commercially sold as Zant currants. Black currant has another common names including, European black currant, Quincy berries, Kurokarin, grosellera Negro (spinach name), (raisins), Corans (English) Cassissier in French (3). Aside from high content of vitamin C, the black currant contain variety of different photochemical possessing antioxidant and free radical scavenging called flavonoids .including Quercetin, Myricetin ,and Kaempherol $(4,5)$. And at least 15 different phenolic compound including onthocyanins and proanthocyanidin $(4,6,7,8)$. Resveratol is another grapes healthful compounds which are related to procyanidins, were found mainly in 
the skin of grapes, reveratol has gained much popularity as an antioxidant supplement (9). Today, health care professionals use standardized extract of grape seed (fresh and skin) to treat arrange of health problem related to free radical damage, including age related disease, DNA damage, cancer, blood sugar regulating problems and heart disease (10). Grapes poanthocyanidin (PCOS) have been shown potent antioxidant effects that significantly inhibit lipid peroxidation of polyunsaturated fatty acid in animals \& in vitro studies (1, 11). Polyphenol in different grapes species potentially inhibited reactive oxygen species activities implicated in microvascular injury (12). Black currant concentrate prepared from black currant juice with high polyphenolic compound enhances synthesis of $\mathrm{NO}$ with subsequent induction of endothelium dependent vasorelaxation in rat aorta (13). Although grape seed fruit has been suggested for improving diseased condition, black currant has gained little attention. Further research is needed in this area before strong recommendations can be made. Accordingly the hypothesis that aqueous extract of black currant concentrate (Vitis vinifera.L) might affect several measures of vascular health was tested in rats exposed experimentally to oxidative stress by $0.5 \% \mathrm{H} 2 \mathrm{O} 2$ in drinking water. It also aimed at comparing the prophylactic effect of the black currant concentrate with that of vit $\mathrm{E}$.

\section{Material and Methods}

Forty (40) male Albino rats were randomly divided into four groups (10 rat/ group) and were treated daily for six weeks as follows: 1-Group I: Rats of this group were received $1 \mathrm{ml}$ of sun flower oil daily by oral intubations using gavage needle and served as control group.

2- Group П: Animal of this group were subjected to ad libitum supply of drinking water containing $0.5 \% \mathrm{H} 2 \mathrm{O} 2$.

3- Group Ш: The rats of this group were administered daily $400 \mathrm{IU} \backslash \mathrm{kg}$ body weight of vitamin $\mathrm{E}$ diluting in sun flower oil using gavage needle (14) plus $0.5 \% \mathrm{H} 2 \mathrm{O} 2$ in drinking water.

4- Group IV: animal of this group were intubated daily $60 \mathrm{mg} / \mathrm{kg}$ body weight of Crude aqueous extract of black currant concentrate plus $0.5 \% \mathrm{H} 2 \mathrm{O} 2$ in drinking water.

Fasting blood samples were collected at zero, 21, 42 days of experiments Where blood, plasma\& serum were prepared as mentioned previously. Blood samples were used immediately for platelet count (15), while plasma samples were used for measuring prothrombin time (using standard assay (prothrombin time kit) . and serum was used for measurements of lipid profile including serum triacylglycerol (TAG), Total cholesterol (TC), High density Lipoprotein cholesterol (HDL-C)(Enzymatically ,Bicon chemical Kits), Low density lipoprotein cholesterol (LDL-C) and Very low density lipoprotein 
cholesterol(VLDL-C)(16).Statistical analysis of data was performed on the basis of two way analysis of variance (ANOVA) using significant level of $(\mathrm{P}<0.05)$.Specific group Differences were determined using least significant differences LSD (17).

\section{Result}

Statistical differences were absent $(\mathrm{P}>0.05)$ between groups during the pretreated period, however, administration $0.5 \% \mathrm{H} 2 \mathrm{O} 2$ in drinking water alone (group GП) or in combination with vitamin E (group GW) or with Black currant concentrate (group GIV) caused significant decrease $(\mathrm{P}<0.05)$ in PT after 21 days of treatment comparing to the control (table 1).Within the time. Significant reduction $(\mathrm{P}<0.05)$ in mean value of $\mathrm{PT}$ were observed after exposure to $\mathrm{H} 2 \mathrm{O} 2$ alone (group GП) or in combination with vitamin E (group Ш) comparing to the pretreated period. While oral intubations of black currant concentrate in addition to $0.5 \% \mathrm{H} 2 \mathrm{O} 2$ in drinking water caused significant increment $(\mathrm{P}<0.05)$ in PT value $(20.45 \pm 1.25)$ after 42 days of treatment comparing to the pretreated period $(17.14 \pm 0.30)$.

While there were non significant differences $(\mathrm{p}>0.05)$ in total numbers of platelet (platelet/mm3) between experimental groups in the pretreated period (table 2),

Tables 3, 4, 5, 6, 7, illustrated the mean value of TC, TAG, HDL-C, LDL-C and VLDL-C concentration in serum of control and three treated groups along the experimental period. Table(3) showed a general trend for the TC value to increase in $0.5 \% \mathrm{H} 2 \mathrm{O} 2$ treated groups as compared to control group \& another two treated groups (GW, and GIV). This increment reach stastical significance $(\mathrm{p}<0.05)$ at the day 21 and 42 of the experiment. Besides oral intubations of black currant concentrate concurrently with $\mathrm{H} 2 \mathrm{O} 2$ in drinking water significantly suppressed $(\mathrm{p}<0.05)$ the elevated TC concentration at days 42 of experiment $(85.67 \pm 6.2)$ compared to the pretreated period.

The result also showed that exposure of animals to $0.5 \% \mathrm{H} 2 \mathrm{O} 2$ in drinking water significantly increased $(\mathrm{p}<0.05)$ the mean of value of TAG concentration of day $42(83.37 \pm 6.8)$ of the experiment comparing to the control $(68.02 \pm 2.93)$ and GW $(63.37 \pm 3.37)$ and GIV $(62.52 \pm 3.02)$ treated groups. It appears that black currant concentrate and vitamin $\mathrm{E}$ reduced the elevated TAG concentration caused by $\mathrm{H} 2 \mathrm{O} 2$ exposure.(table) 7 .

A significant increase $(\mathrm{p}<0.05)$ in mean value of serum HDL-C concentration were detected at days $21 \& 42$ in GIV (black currant group) with a mean value of $(43.19 \pm 4.41)$ and $(47.44 \pm 2.09)$ for day $21 \& 42$ respectively and at day 42 in $\mathrm{GW}(42.82 \pm 2.28)$ comparing to $\mathrm{H} 2 \mathrm{O} 2$ treated group. However, there is clear decrease $(\mathrm{p}<0.05)$ in serum HDL-C concentration in GП $(30.69 \pm 1.46)$ 
comparing to control group $(35.89 \pm 1.8)$ at the end of experiment.(table 5).Moreover increasing the time of intubation of black currant had positive effect on HDL-C concentration.

It seems that vitamin $\mathrm{E}$ intubations concurrently with $\mathrm{H} 2 \mathrm{O} 2$ normalized LDL-C value with that control at day $21(75.50 \pm 5.12) \&$ the value reach below that of control at the end of experiment. $(63.26 \pm 2.8)$ compared to the pretreated period $(75.23 \pm 5.21)$.

Beside, oral intubations of black currant concentrate (GIV) Significantly suppressed $(\mathrm{p}<0.05)$ the mean value of LDL-C at the day $21 \& 42$ of treatment compared to $\mathrm{H} 2 \mathrm{O} 2$ treated group ,the highest reduction in LDL-C concentration were recorded at day 42 of treatment with mean value of $(50.73 \pm 7.87)$ table (6).

The mean value of serum VLDL-C concentration in different treated and control groups were clarified in table (7). The cholesterol concentration in VLDL increased significantly $(\mathrm{p}<0.05)$ after exposure to $\mathrm{H} 2 \mathrm{O} 2$ comparing to control and GW \& GIV treated group. Such increment was observed at the end of experiment (day 42). On the other hand, oral intubations of vitamin $\mathrm{E}$ or black currant concentrate in combination with $\mathrm{H} 2 \mathrm{O} 2$ caused significant depression $(\mathrm{p}<0.05)$ in mean value of serum VLDL-C concentration compared to $\mathrm{H} 2 \mathrm{O} 2$ treated groups table (7). 
Table (1): Effect of black currant concentrate (Vitis vinfera.L) and vitamin $\mathrm{E}$ on prothrombin time (second) in $\mathrm{H2O} 2$ treated rats.

Values are expressed as Means $\pm \mathrm{SE}, \mathrm{n}=10$ / group

\begin{tabular}{|c|c|c|c|c|}
\hline $\begin{array}{l}\text { Group } \\
\text { Time } \\
\text { days }\end{array}$ & Group I & Group $\Pi$ & Group Ш & Group IV \\
\hline $\begin{array}{l}\text { Pre- } \\
\text { treated } \\
\text { period }\end{array}$ & $\begin{array}{c}17.37 \pm 0.5 \\
\mathrm{~A} \mathrm{a}\end{array}$ & $\begin{array}{c}17.47 \pm 0.40 \\
\mathrm{~A} \mathrm{a}\end{array}$ & $\begin{array}{c}17.58 \pm 0.45 \\
\mathrm{~A} \mathrm{a}\end{array}$ & $\begin{array}{c}17.14 \pm 0.30 \\
\mathrm{~A} \mathrm{a}\end{array}$ \\
\hline 21 days & $\begin{array}{c}18.02 \pm 0.4 \\
\mathrm{~A} \mathrm{a}\end{array}$ & $\begin{array}{c}15.52 \pm 0.86 \\
\mathrm{~B} \mathrm{~b}\end{array}$ & $\begin{array}{c}13.76 \pm 1.51 \\
\mathrm{Cb}\end{array}$ & $\begin{array}{c}14.7 \pm 1.43 \\
\text { B b }\end{array}$ \\
\hline 42days & $\begin{array}{c}18.32 \pm 1.04 \\
\mathrm{~A} \mathrm{a}\end{array}$ & $\begin{array}{c}10.20 \pm 0.56 \\
\text { B C }\end{array}$ & $\begin{array}{c}15.83 \pm 1.02 \\
\mathrm{Cc}\end{array}$ & $\begin{array}{c}20 \pm 1.25 \\
\text { D c }\end{array}$ \\
\hline
\end{tabular}

$\mathrm{GI}=$ considered as control group

$\mathrm{G} \Pi=$ rats received $0.5 \%$ of $\mathrm{H} 2 \mathrm{O} 2$ in drinking water

$\mathrm{GW}=$ rats received (400 IU/Kg/day) of vitamin E plus $0.5 \% \mathrm{H} 2 \mathrm{O} 2$ in drinking water

$\mathrm{GIV}=$ rats received $(60 \mathrm{mg} / \mathrm{kg} \mathrm{B} . \mathrm{W})$ of black currant concentrate plus $0.5 \% \mathrm{H} 2 \mathrm{O} 2$ in drinking water.

Capital letters denote between groups differences, $\mathrm{p}<0.05$ vs. control.

Small letters denote within group differences, $\mathrm{p}<0.05$ vs. pretreated period. 
Iraqi Journal of Veterinary Medicine Vol. 32, No. 2, 2008

Table (2): Effect of black currant concentrates (Vitis vinfera. L) And vitamin $\mathrm{E}$ on platelet count (platelet/mm3) in $\mathrm{H2O}$ treated rats

Values are expressed as Means $\pm \mathrm{SE}, \mathbf{n}=10$ / group

\begin{tabular}{|c|c|c|c|c|}
\hline $\begin{array}{l}\text { Group } \\
\text { Time } \\
\text { days }\end{array}$ & Group I & Group $\Pi$ & Group Ш & Group IV \\
\hline $\begin{array}{l}\text { Pre- } \\
\text { treated } \\
\text { period }\end{array}$ & $\begin{array}{c}316000 \pm \\
48352 \\
\mathrm{~A} \mathrm{a}\end{array}$ & $\begin{array}{c}315833 \pm 46658.7 \\
\text { A a }\end{array}$ & $\begin{array}{c}347500 \pm 42994.5 \\
\text { A a }\end{array}$ & $\begin{array}{c}358600 \pm 36452.9 \\
\text { A a }\end{array}$ \\
\hline 21 days & $\begin{array}{c}301066 \pm 10506 \\
\text { A a }\end{array}$ & $\begin{array}{c}427833 \pm 40672 \\
\text { B b }\end{array}$ & $\begin{array}{c}350833 \pm 42977.9 \\
\text { A a }\end{array}$ & $\begin{array}{c}360333 \pm 35497.5 \\
\mathrm{~A} \mathrm{a}\end{array}$ \\
\hline 42days & $\begin{array}{c}324035 \pm 17490 \\
\text { A a }\end{array}$ & $\begin{array}{c}568666 \pm 30967 \\
\text { B c }\end{array}$ & $\begin{array}{c}473000 \pm 20373.3 \\
\mathrm{C} \mathrm{b}\end{array}$ & $\begin{array}{c}469333 \pm 194966 \\
\mathrm{C} \mathrm{b}\end{array}$ \\
\hline
\end{tabular}

$\mathrm{GI}=$ considered as control group

$\mathrm{G}=$ rats received $0.5 \%$ of $\mathrm{H} 2 \mathrm{O} 2$ in drinking water,

$\mathrm{GW}=$ rats received (400 $\mathrm{IU} / \mathrm{Kg} /$ day) of vitamin E plus $0.5 \% \mathrm{H} 2 \mathrm{O} 2$ in drinking Water.

$\mathrm{GIV}=$ rats received $(60 \mathrm{mg} / \mathrm{kg} \mathrm{B} . \mathrm{W})$ of black currant concentrate plus $0.5 \% \mathrm{H} 2 \mathrm{O} 2$ in drinking water.

Capital letters denote between groups differences, $\mathrm{p}<0.05$ vs. control.

Small letters denote within group differences, $\mathrm{p}<0.05$ vs. pretreated period. 
Iraqi Journal of Veterinary Medicine Vol. 32, No. 2, 2008

Table (3) Effect of black currant concentrate (Vitis Vinfera. L) and vitamin $\mathbf{E}$ on serum total cholesterol (TC) concentration rats.

Values are expressed as Means $\pm \mathrm{SE}, \mathbf{n}=10$ / group

\begin{tabular}{|c|c|c|c|c|}
\hline $\begin{array}{l}\text { Group } \\
\text { Time } \\
\text { days }\end{array}$ & Group I & Group $\Pi$ & Group Ш & Group IV \\
\hline $\begin{array}{l}\text { Pre- treated } \\
\text { period }\end{array}$ & $\begin{array}{c}97.32 \pm 4 \\
\mathrm{~A} \mathrm{a}\end{array}$ & $\begin{array}{c}96.68 \pm 3.7 \\
\mathrm{~A} \mathrm{a}\end{array}$ & $\begin{array}{c}97.99 \pm 5.8 \\
\mathrm{~A} \mathrm{a}\end{array}$ & $\begin{array}{c}98.93 \pm 4 \\
\mathrm{~A} \mathrm{a}\end{array}$ \\
\hline 21 days & $\begin{array}{c}98.40 \pm 4.6 \\
\mathrm{~A} \mathrm{a}\end{array}$ & $\begin{array}{c}114.4 \pm 3.91 \\
\text { B b }\end{array}$ & $\begin{array}{c}99.13 \pm 5.7 \\
\mathrm{~A} \mathrm{a}\end{array}$ & $\begin{array}{c}92.81 \pm 5.6 \\
\mathrm{~A} \mathrm{a}\end{array}$ \\
\hline 42days & $\begin{array}{c}95.71 \pm 3.5 \\
\mathrm{~A} \mathrm{a}\end{array}$ & $\begin{array}{c}117.97 \pm 4.24 \\
\text { B b }\end{array}$ & $\begin{array}{c}93.42 \pm 3.8 \\
\mathrm{~A} \mathrm{a}\end{array}$ & $\begin{array}{c}85.67 \pm 6.2 \\
\mathrm{~A} \mathrm{~b}\end{array}$ \\
\hline
\end{tabular}

$\mathrm{GI}=$ considered as control group

$\mathrm{G} \Pi=$ rats received $0.5 \%$ of $\mathrm{H} 2 \mathrm{O} 2$ in drinking water

$\mathrm{G} U=$ rats received $(400 \mathrm{IU} / \mathrm{Kg} /$ day $)$ of vitamin $\mathrm{E}$ plus $0.5 \% \mathrm{H} 2 \mathrm{O} 2$ in drinking water.

$\mathrm{GIV}=$ rats received $(60 \mathrm{mg} / \mathrm{kg} \mathrm{B}$.W $)$ of black currant concentrate plus $0.5 \% \mathrm{H} 2 \mathrm{O} 2$ in drinking water.

Capital letters denote between groups differences, $\mathrm{p}<0.05$ vs. control.

Small letters denote within group differences, $\mathrm{p}<0.05$ vs. pretreated period. 
Iraqi Journal of Veterinary Medicine Vol. 32, No. 2, 2008

Table (4): Effect of black currant concentrate (Vitis vinfera.L) and vitamin $\mathbf{E}$ on serum triacylglycerol (TAG) concentration.

Values are expressed as Means $\pm \mathrm{SE}, \mathrm{n}=10$ / group

\begin{tabular}{|c|c|c|c|c|}
\hline $\begin{array}{l}\text { Group } \\
\text { Time } \\
\text { days }\end{array}$ & Group I & Group $\Pi$ & Group Ш & Group IV \\
\hline $\begin{array}{l}\text { Pre- } \\
\text { treated } \\
\text { period }\end{array}$ & $\begin{array}{c}63.96 \pm 2.03 \\
\mathrm{~A} \mathrm{a}\end{array}$ & $\begin{array}{c}64.24 \pm 1.28 \\
\mathrm{~A} \mathrm{a}\end{array}$ & $\begin{array}{c}65.04 \pm 4.09 \\
\mathrm{~A} \mathrm{a}\end{array}$ & $\begin{array}{c}61.98 \pm 4.07 \\
\mathrm{~A} \mathrm{a}\end{array}$ \\
\hline 21 days & $\begin{array}{c}66.48 \pm 2.54 \\
\mathrm{~A} \mathrm{a}\end{array}$ & $\begin{array}{c}68.72 \pm 4.09 \\
\mathrm{~A} \mathrm{a}\end{array}$ & $\begin{array}{c}67.34 \pm 4.15 \\
\mathrm{~A} \mathrm{a}\end{array}$ & $\begin{array}{c}64.61 \pm 4.07 \\
\mathrm{~A} \mathrm{a}\end{array}$ \\
\hline 42days & $\begin{array}{c}68.02 \pm 2.93 \\
\mathrm{~A} \mathrm{a}\end{array}$ & $\begin{array}{c}83.15 \pm 6.8 \\
\text { B b }\end{array}$ & $\begin{array}{c}63.37 \pm 3.37 \\
\mathrm{~A} \mathrm{a}\end{array}$ & $\begin{array}{c}62.52 \pm 3.02 \\
\mathrm{~A} \mathrm{a}\end{array}$ \\
\hline
\end{tabular}

$\mathrm{GI}=$ considered as control group

$\mathrm{G} \Pi=$ rats received $0.5 \%$ of $\mathrm{H} 2 \mathrm{O} 2$ in drinking water

$\mathrm{G} \amalg=$ rats received (400 IU/Kg/day) of vitamin E plus $0.5 \% \mathrm{H} 2 \mathrm{O} 2$ in drinking water.

$\mathrm{GIV}=$ rats received $(60 \mathrm{mg} / \mathrm{kg} \mathrm{B} . \mathrm{W})$ of black currant concentrate plus $0.5 \% \mathrm{H} 2 \mathrm{O} 2$ in drinking water.

Capital letters denote between groups differences, $\mathrm{p}<0.05$ vs. control.

Small letters denote within group differences, $\mathrm{p}<0.05$ vs. pretreated period. 
Iraqi Journal of Veterinary Medicine Vol. 32, No. 2, 2008

Table (5) Effect of black currant concentrate ( E on serum high density lipoprotein -cholesterol concentration in $\mathrm{H} 2 \mathrm{O2}$ treated rats.

Values are expressed as Means $\pm \mathrm{SE}, \mathrm{n}=\mathbf{1 0}$ / group

\begin{tabular}{|c|c|c|c|c|}
\hline Group & Group I & Group П & Group Ш & Group IV \\
$\begin{array}{c}\text { Time } \\
\text { Days }\end{array}$ & & & \\
\hline $\begin{array}{c}\text { Pre- treated } \\
\text { Period }\end{array}$ & $\begin{array}{c}31.99 \pm 0.97 \\
\text { A a }\end{array}$ & $\begin{array}{c}31.86 \pm 0.92 \\
\text { A a }\end{array}$ & $\begin{array}{c}35.76 \pm 1.95 \\
\text { A a }\end{array}$ & $\begin{array}{c}35.91 \pm 1.29 \\
\text { A a }\end{array}$ \\
\hline 21 days & $\begin{array}{c}35.69 \pm 0.74 \\
\text { A a }\end{array}$ & $\begin{array}{c}33.25 \pm 2.12 \\
\text { A a }\end{array}$ & $\begin{array}{c}36.92 \pm 2.45 \\
\text { A a }\end{array}$ & $\begin{array}{c}43.19 \pm 4.41 \\
\text { B b }\end{array}$ \\
\hline 42 days & $\begin{array}{c}35.89 \pm 1.8 \\
\text { A a }\end{array}$ & $\begin{array}{c}30.69 \pm 1.46 \\
\text { B a }\end{array}$ & $\begin{array}{c}42.82 \pm 2.28 \\
\text { C b }\end{array}$ & $\begin{array}{c}47.44 \pm 2.09 \\
\text { D c }\end{array}$ \\
\hline
\end{tabular}

GI= considered as control group

$\mathrm{G} \Pi=$ rats received $0.5 \%$ of $\mathrm{H} 2 \mathrm{O} 2$ in drinking water

$\mathrm{GW}=$ rats received (400 $\mathrm{IU} / \mathrm{Kg} /$ day) of vitamin E plus $0.5 \% \mathrm{H} 2 \mathrm{O} 2$ in drinking water.

$\mathrm{GIV}=$ rats received $(60 \mathrm{mg} / \mathrm{kg} \mathrm{B} . \mathrm{W})$ of black currant concentrate plus $0.5 \% \mathrm{H} 2 \mathrm{O} 2$ in drinking water.

Capital letters denote between groups differences, $\mathrm{p}<0.05$ vs. control.

Small letters denote within group differences, $\mathrm{p}<0.05$ vs. pretreated period. 
Iraqi Journal of Veterinary Medicine Vol. 32, No. 2, 2008

\section{Table (6) Effect of black currant concentrate (Vitis Vinfera.L) and vitamin $\mathbf{E}$ on serum low density lipoprotein cholesterol (LDL-C) concentration in $\mathrm{H} 2 \mathrm{O} 2$ treated rats.}

Values are expressed as Means \pm SE, $n=10 /$ group

\begin{tabular}{|c|c|c|c|c|}
\hline $\begin{array}{l}\text { Group } \\
\text { Time }\end{array}$ & Group I & Group $\Pi$ & Group Ш & Group IV \\
\hline $\begin{array}{c}\text { Pre- } \\
\text { treated } \\
\text { Period }\end{array}$ & $\begin{array}{c}77.99 \pm 3.7 \\
\mathrm{~A} \mathrm{a}\end{array}$ & $\begin{array}{c}77.68 \pm 3.35 \\
\mathrm{~A} \mathrm{a}\end{array}$ & $\begin{array}{c}75.23 \pm 5.21 \\
\mathrm{~A} \mathrm{a}\end{array}$ & $\begin{array}{c}75.41 \pm 4.02 \\
\mathrm{~A} \mathrm{a}\end{array}$ \\
\hline 21 days & $\begin{array}{c}76.97 \pm 6.07 \\
\mathrm{~A} \mathrm{a}\end{array}$ & $\begin{array}{c}94.89 \pm 4.46 \\
\text { B b }\end{array}$ & $\begin{array}{c}75.50 \pm 5.12 \\
\mathrm{~A} \mathrm{a}\end{array}$ & $\begin{array}{c}62.45 \pm 4.10 \\
\mathrm{Cb}\end{array}$ \\
\hline 42days & $\begin{array}{c}76.10 \pm 4.25 \\
\mathrm{~A} \mathrm{a}\end{array}$ & $\begin{array}{c}103.91 \pm 5.27 \\
\text { B c }\end{array}$ & $\begin{array}{c}63.26 \pm 2.80 \\
\mathrm{C} \mathrm{b}\end{array}$ & $\begin{array}{c}50.73 \pm 7.87 \\
\mathrm{D} \mathrm{c}\end{array}$ \\
\hline
\end{tabular}

$\mathrm{GI}=$ considered as control group

$\mathrm{G} \Pi=$ rats received $0.5 \%$ of $\mathrm{H} 2 \mathrm{O} 2$ in drinking water

$\mathrm{G} \amalg=$ rats received $(400 \mathrm{IU} / \mathrm{Kg} /$ day $)$ of vitamin $\mathrm{E}$ plus $0.5 \% \mathrm{H} 2 \mathrm{O} 2$ in drinking water.

$\mathrm{GIV}=$ rats received $(60 \mathrm{mg} / \mathrm{kg} \mathrm{B} . \mathrm{W})$ of black currant concentrate plus $0.5 \% \mathrm{H} 2 \mathrm{O} 2$ in drinking water.

Capital letters denote between groups differences, $\mathrm{p}<0.05$ vs. control.

Small letters denote within group differences, $\mathrm{p}<0.05$ vs. pretreated period. 


\section{Table (7) Effect of black currant concentrate (Vitis Vinfera.L) and vitamin $\mathbf{E}$ on serum very low density lipoprotein cholesterol (VLDL-C) concentration in $\mathrm{H} 2 \mathrm{O} 2$ treated rats.}

Values are expressed as Means $\pm \mathrm{SE}, \mathrm{n}=10$ / group

\begin{tabular}{|c|c|c|c|c|}
\hline $\begin{array}{l}\text { Group } \\
\text { Time } \\
\text { days }\end{array}$ & Group I & Group $\Pi$ & Group Ш & Group IV \\
\hline $\begin{array}{l}\text { Pre- } \\
\text { treated } \\
\text { Period }\end{array}$ & $\begin{array}{c}12.79 \pm 0.40 \\
\mathrm{~A} \mathrm{a}\end{array}$ & $\begin{array}{c}12.84 \pm 0.36 \\
\mathrm{~A} \mathrm{a}\end{array}$ & $\begin{array}{c}13 \pm 0.81 \\
\text { A a }\end{array}$ & $\begin{array}{c}12.39 \pm 0.81 \\
\mathrm{~A} \mathrm{a}\end{array}$ \\
\hline 21 days & $\begin{array}{c}13.69 \pm 0.74 \\
\mathrm{~A} \mathrm{a}\end{array}$ & $\begin{array}{c}13.74 \pm 0.85 \\
\text { A a }\end{array}$ & $\begin{array}{c}13.46 \pm 0.82 \\
\mathrm{~A} \mathrm{a}\end{array}$ & $\begin{array}{c}12.83 \pm 0.82 \\
\mathrm{~A} \mathrm{a}\end{array}$ \\
\hline 42days & $\begin{array}{c}14.23 \pm 0.95 \\
\mathrm{~A} \mathrm{a}\end{array}$ & $\begin{array}{c}16.62 \pm 1.36 \\
\mathrm{~B} \mathrm{~b}\end{array}$ & $\begin{array}{c}12.66 \pm 0.67 \\
\mathrm{~A} \mathrm{a}\end{array}$ & $\begin{array}{c}12.50 \pm 0.60 \\
\mathrm{~A} \mathrm{a}\end{array}$ \\
\hline
\end{tabular}

$\mathrm{GI}=$ considered as control group

$\mathrm{G}=$ rats received $0.5 \%$ of $\mathrm{H} 2 \mathrm{O} 2$ in drinking water

$\mathrm{G} \amalg=$ rats received (400 IU/Kg/day) of vitamin E plus $0.5 \% \mathrm{H} 2 \mathrm{O} 2$ in drinking water.

$\mathrm{GIV}=$ rats received $(60 \mathrm{mg} / \mathrm{kg} \mathrm{B} . \mathrm{W})$ of black currant concentrate plus $0.5 \% \mathrm{H} 2 \mathrm{O} 2$ in drinking water.

Capital letters denote between groups differences, $\mathrm{p}<0.05$ vs. control.

Small letters denote within group differences, $\mathrm{p}<0.05$ vs. pretreated period.

\section{Histological Finding}

The histological structure of heart and aorta of untreated rats (GI) were shown in figures $(1,2)$. Oral intubation of $0.5 \% \mathrm{H} 2 \mathrm{O} 2$ alone (GП) or in combination with vitamin $\mathrm{E}$ (GW) produced atherosclerotic lesions however, the pathological changes were sever in $\mathrm{H} 2 \mathrm{O} 2$ treated group. Fatty changes in cardiac cells with fatty (inflammatory) cells infiltration between the muscle fiber were observed in cardiac muscle of $\mathrm{H} 2 \mathrm{O} 2$ treated groups (fig $3 \& 5$ ).

Thickness of intima in the pulmonary artery with collagen proliferation \& infiltration of foamy cells (atheromatous lesions) in the subintimal layers causing narrowing of blood vessels were observed in figure (4) related to section in pulmonary artery of $\mathrm{H} 2 \mathrm{O} 2$ treated rats. Irregular intima to which 
inflammatory cells were attached and focal foamy cells in the subintimal layer were shown in the aorta of $\mathrm{H} 2 \mathrm{O} 2$ treated group (fig 6). The same pathological changes were observed in the aorta of $\mathrm{H} 2 \mathrm{O} 2+\mathrm{Vt} \mathrm{E}$ (GW) treated groups (fig 9), Histological changes in the heart of same group pointed to the presence of fatty changes in the muscle fiber characterized by clear round vacuoles and oedematus muscle fiber as well as sever inflammatory cell in the epicardium (figs $7 \& 8$ ).

Oral intubation of $60 \mathrm{mg} / \mathrm{Kg}$ B.W.of black currant concentrate concurrently with $0.5 \% \mathrm{H} 2 \mathrm{O} 2$ caused complete regression of lesion in the muscle fiber and heart \& walls of pulmonary artery (fig 10) as well as pathological changes of aorta (fig 11).

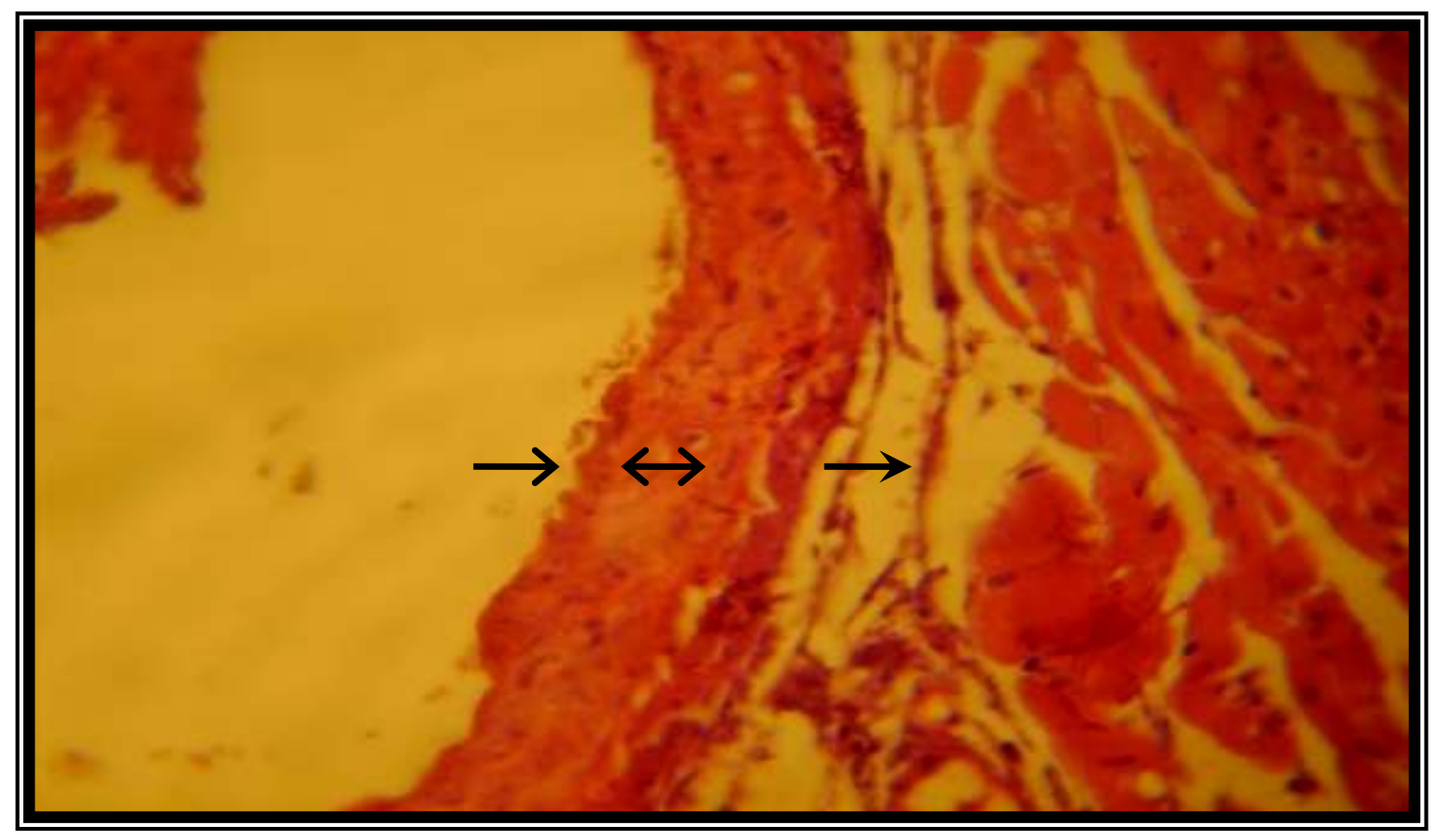

Figure (1) Histological section in heart of control group \& layers of pulmonary Artery $(\longrightarrow)$ intima, $(\leftrightarrow)$ ) muscularis, $(\longrightarrow)$ advantia $H \& E$ 40X. 
Iraqi Journal of Veterinary Medicine Vol. 32, No. 2, 2008

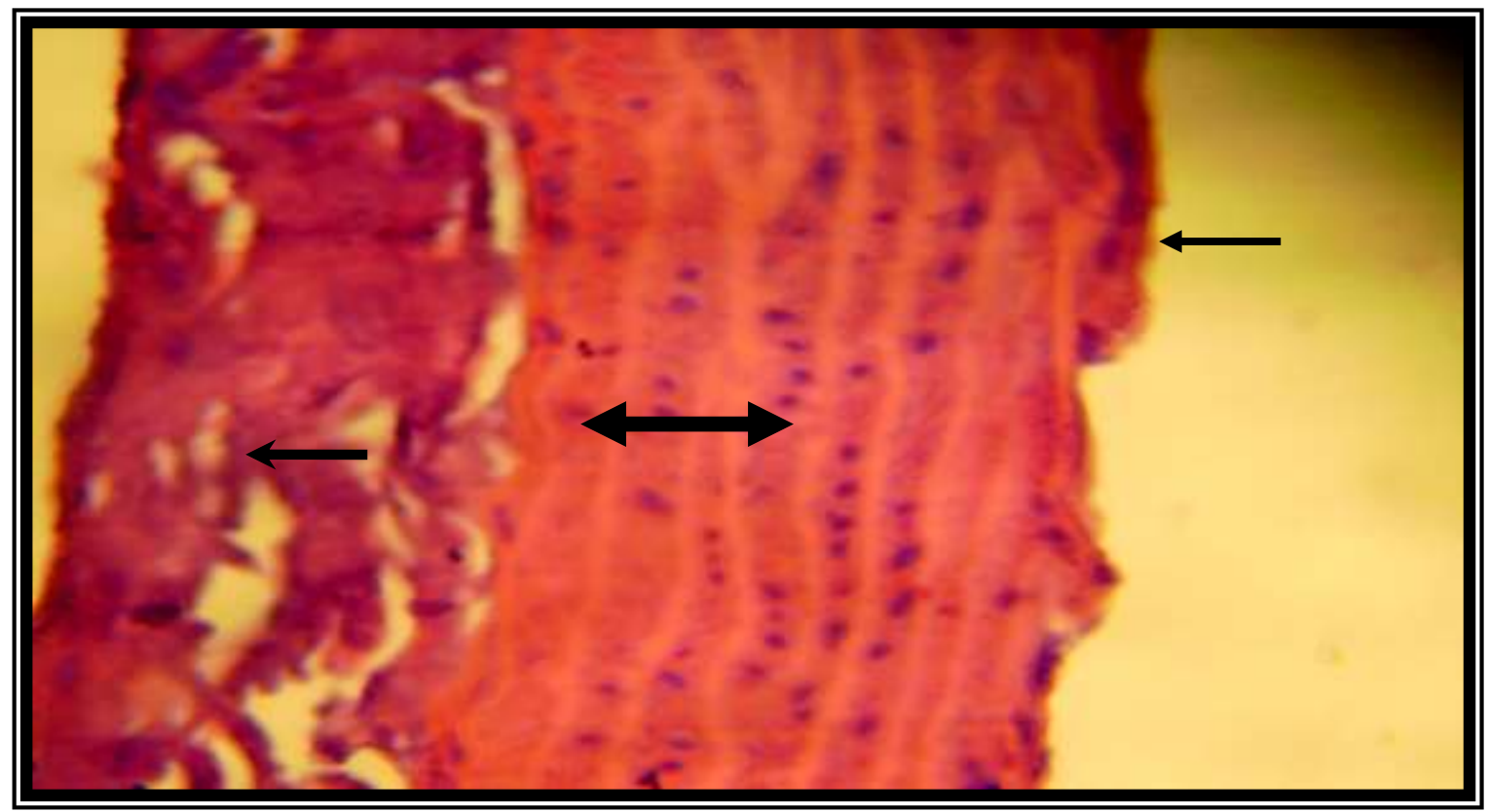

Figure (2) Histological section in layers of Aorta in control group $(\longleftarrow)$ intima, $(\longrightarrow$ )musculari $(\longrightarrow \quad)$ advantia. \& E

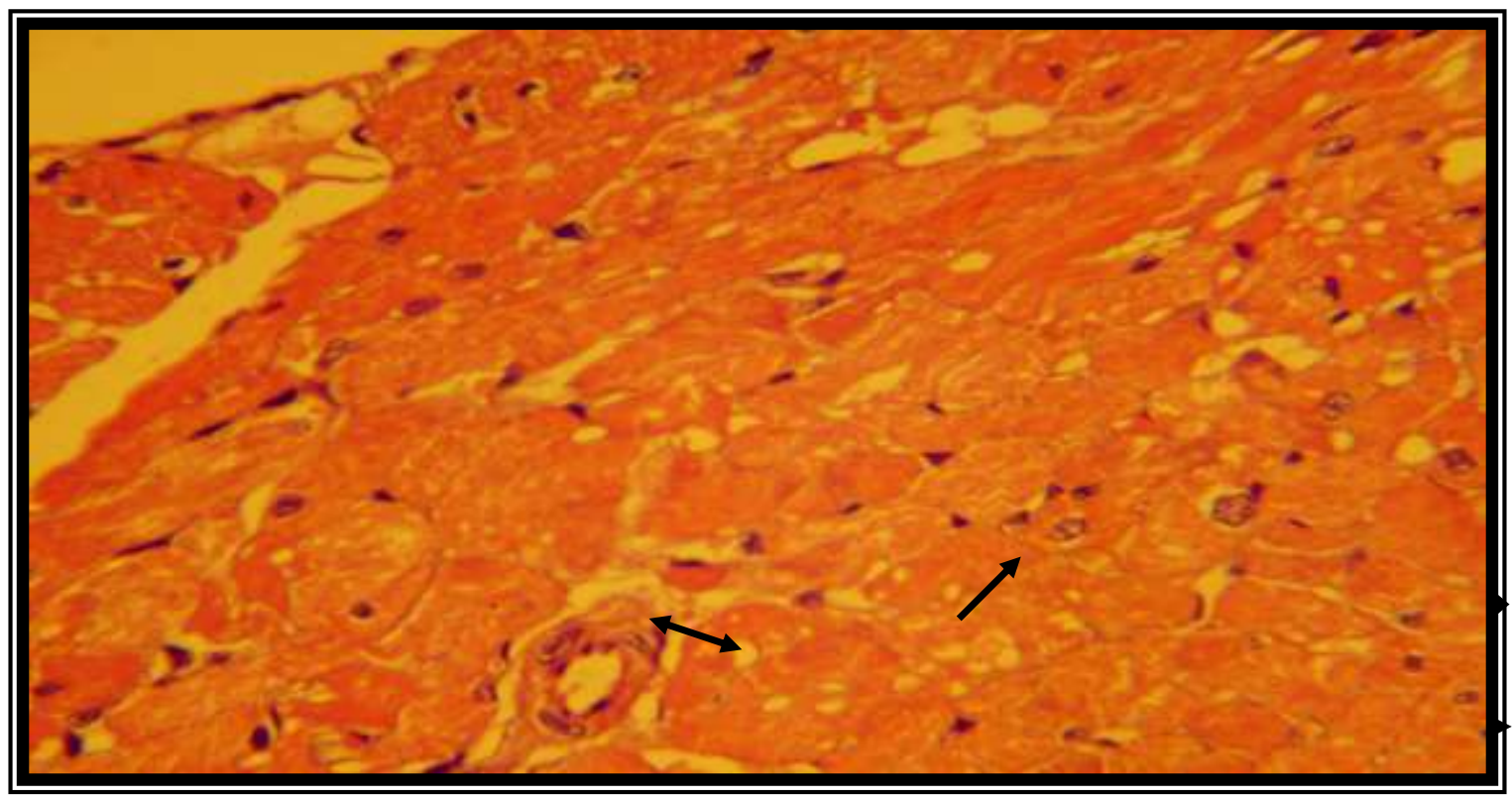

Figure (3) Histological section in heart of $\mathrm{H}_{2} \mathrm{O}_{2}$ treated rats. Note :excessive thickness of intima due to proliferation collagen fiber

$(\nearrow$ ) \& present foamy cells $(\longleftrightarrow)$ H \& E 40X. 
Iraqi Journal of Veterinary Medicine Vol. 32, No. 2, 2008

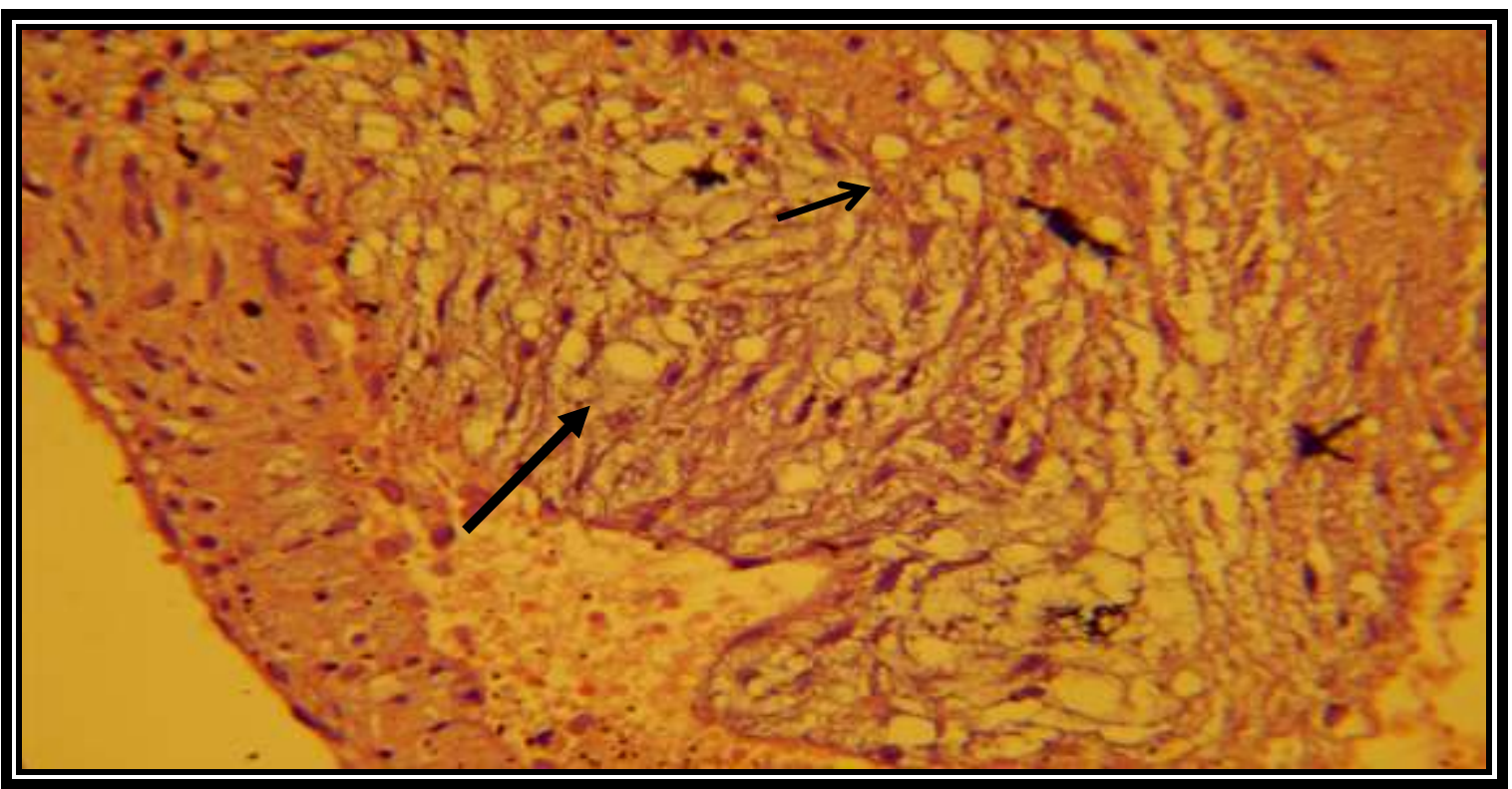

Figure (4) Histological section of pulmonary artery of $\mathrm{H}_{2} \mathrm{O}_{2}$ treated rats dense thickness of intima in muscular layer of blood vessel lead to narrowing of its $(\longrightarrow)$, \& clear rounded vacuole in cytoplasm of cell $(\longrightarrow) \mathrm{H} \& \mathrm{E} 40 \mathrm{X}$..

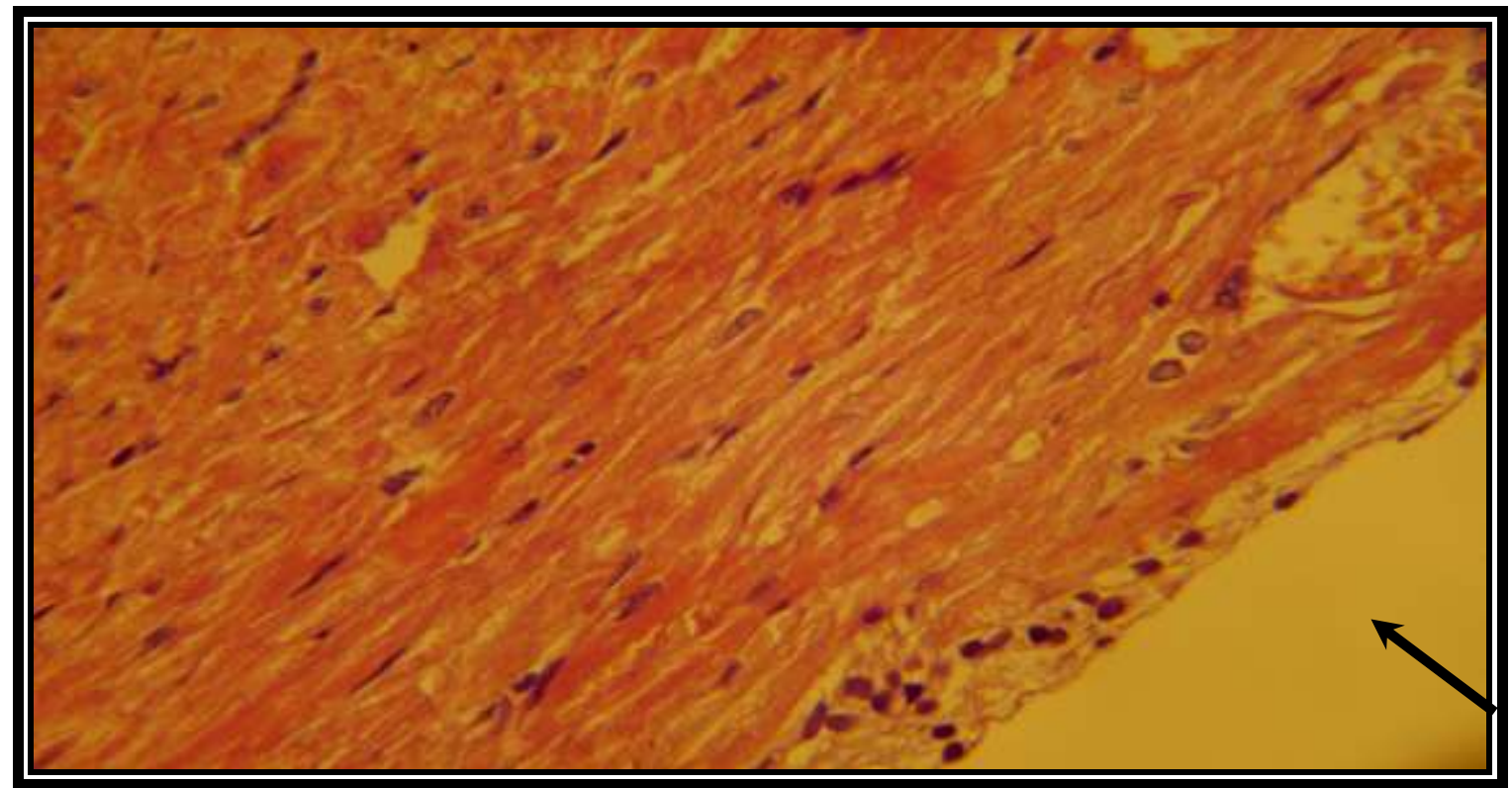

Figure (5) Histological section in heart of 202 treated rats. Note: inflammatory cell infiltration in epicardium $(\rightarrow)$ H \& E 40X. 
Iraqi Journal of Veterinary Medicine Vol. 32, No. 2, 2008

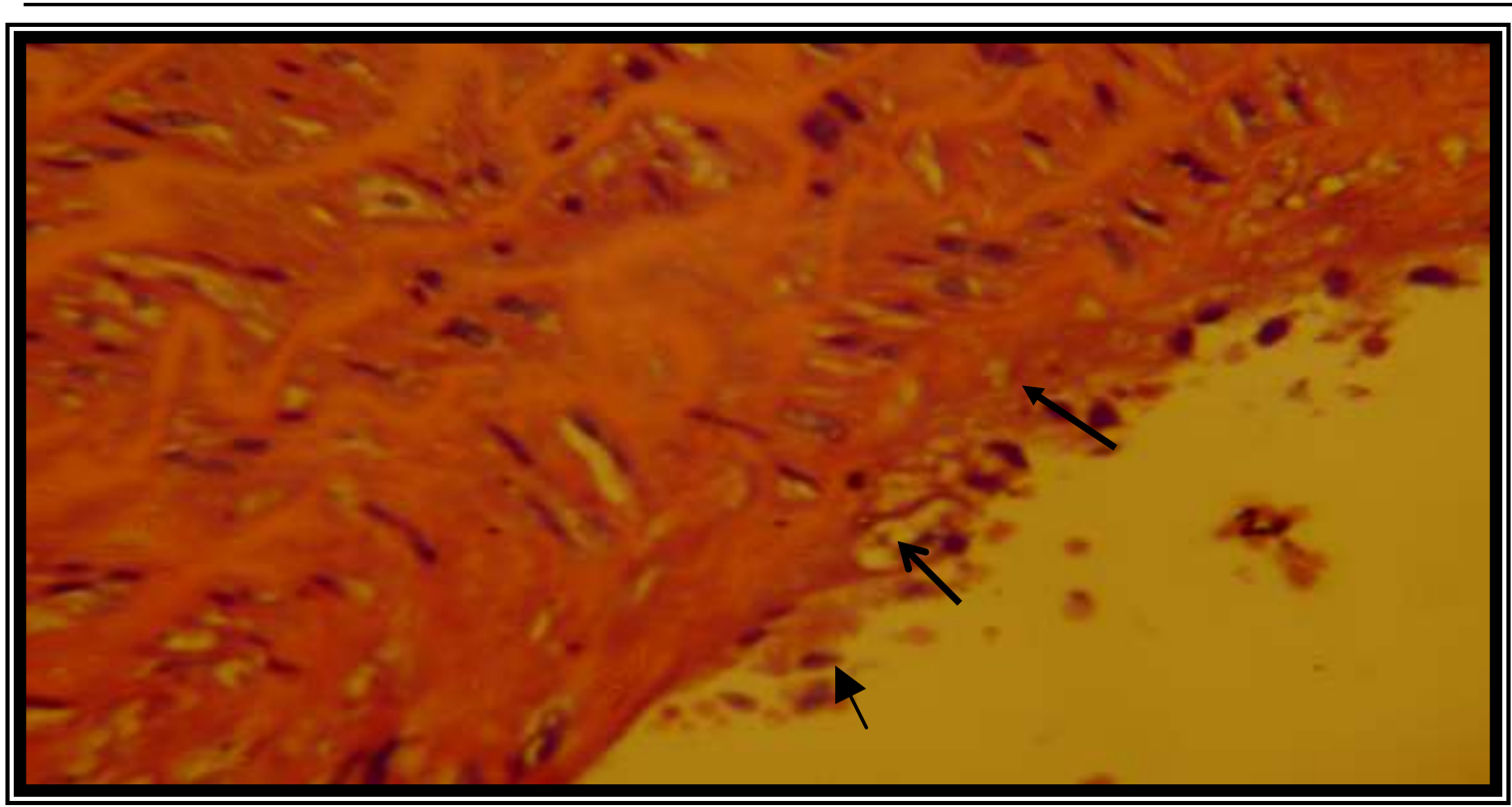

Figure (6) Histological section in Aorta of $\mathrm{H2O}$ treated rats note: irregular of intima $(\longrightarrow)$, with inflammatory cells attachment to it's $(\longrightarrow) \&$ focal foamy cell in sub intimae $(\longrightarrow)$.H \& E 40X.

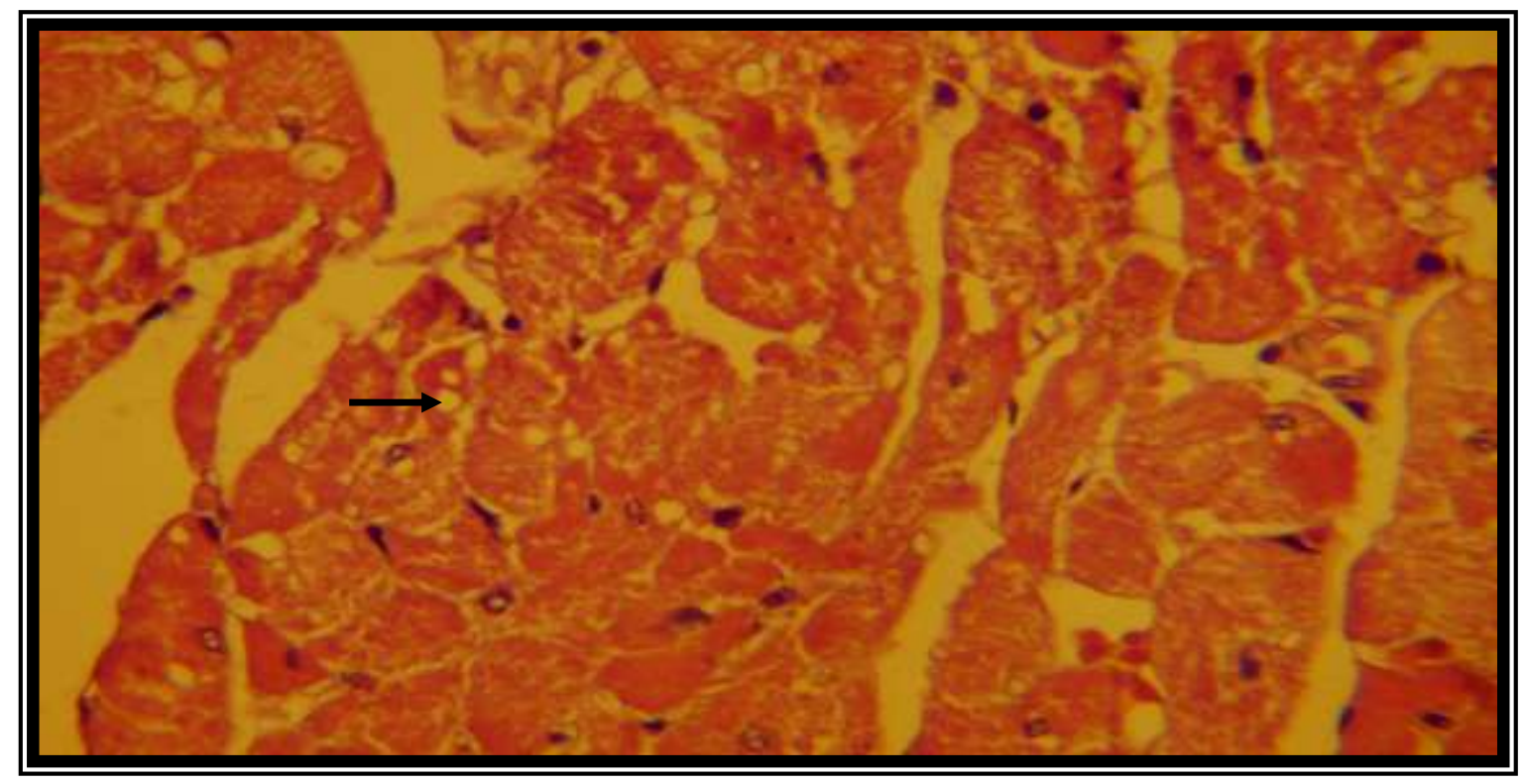

Figure (7) Histological section of heart treated with $\mathrm{H} 2 \mathrm{O} 2$ \& vit E. 2000Note: fatty change in muscles characterized by clear round vacuole with edematous muscles fiber $(\longrightarrow)$ H \& E 40X. 
Iraqi Journal of Veterinary Medicine Vol. 32, No. 2, 2008

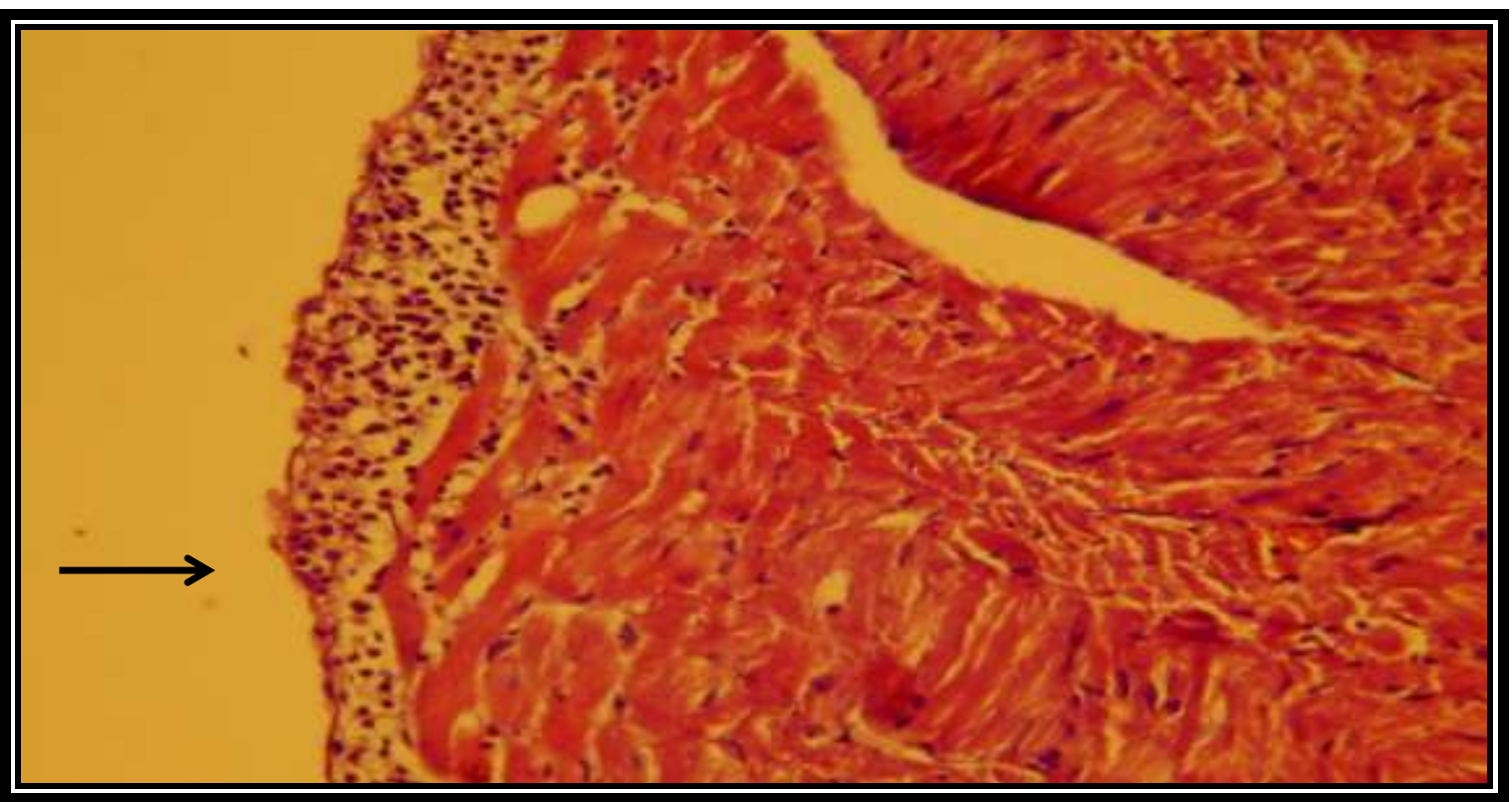

Figure (8) Histological section of heart treated with $\mathrm{H} 2 \mathrm{O} 2$ \& vit E. Note: sever inflammatory cell in epicardium and muscle fiber $(\longrightarrow)$ H \& E 40X.

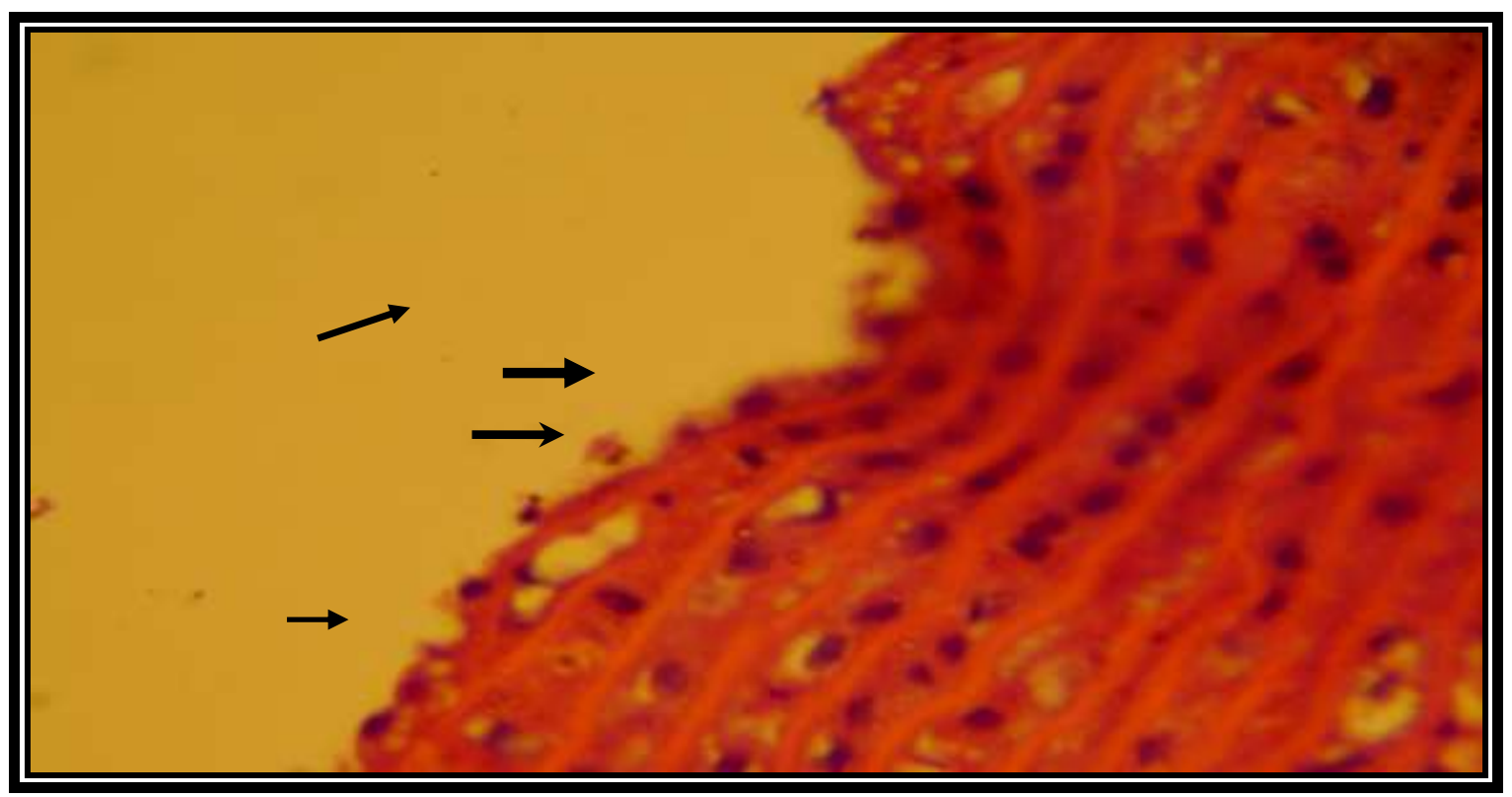

Figure (9) Histological section of aorta treated with $\mathrm{H}_{2} \mathrm{O}_{2} \&$ vit $\mathrm{E}$ Note.Irregular intima $(\longrightarrow) \&$ inflammatory cell attach to it $(\longrightarrow)$, foamy cell with sub intima $(\longrightarrow) \mathrm{H} \& \mathrm{E} 40 \mathrm{X}$. 


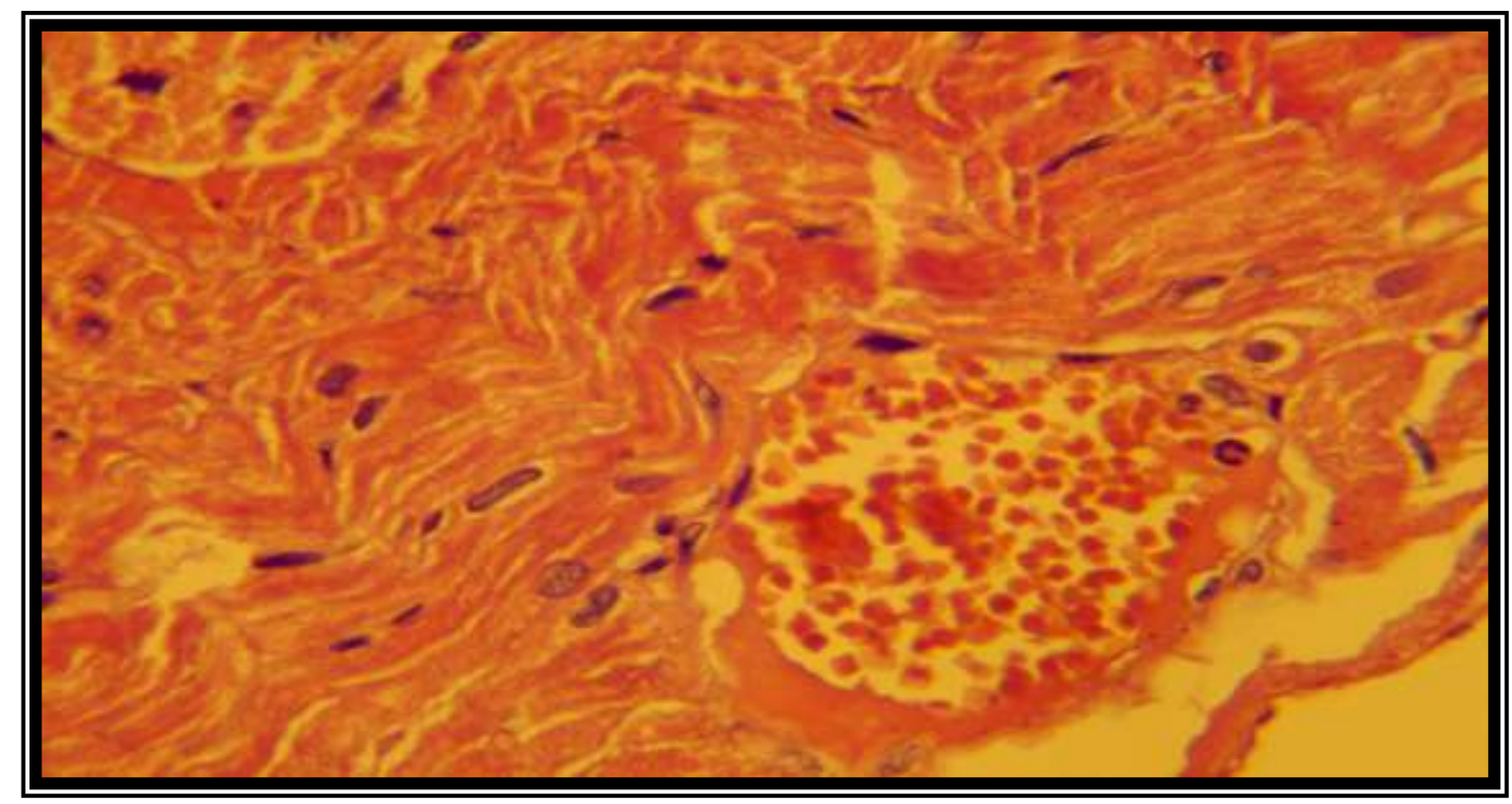

Figure (10) Histological section of heart treated $\mathrm{H}_{2} \mathrm{O}_{2}$ Plus black currant complete concentrate regression of lesion in the muscle fiber $\&$ wall of pulmonary artery H.E 40X

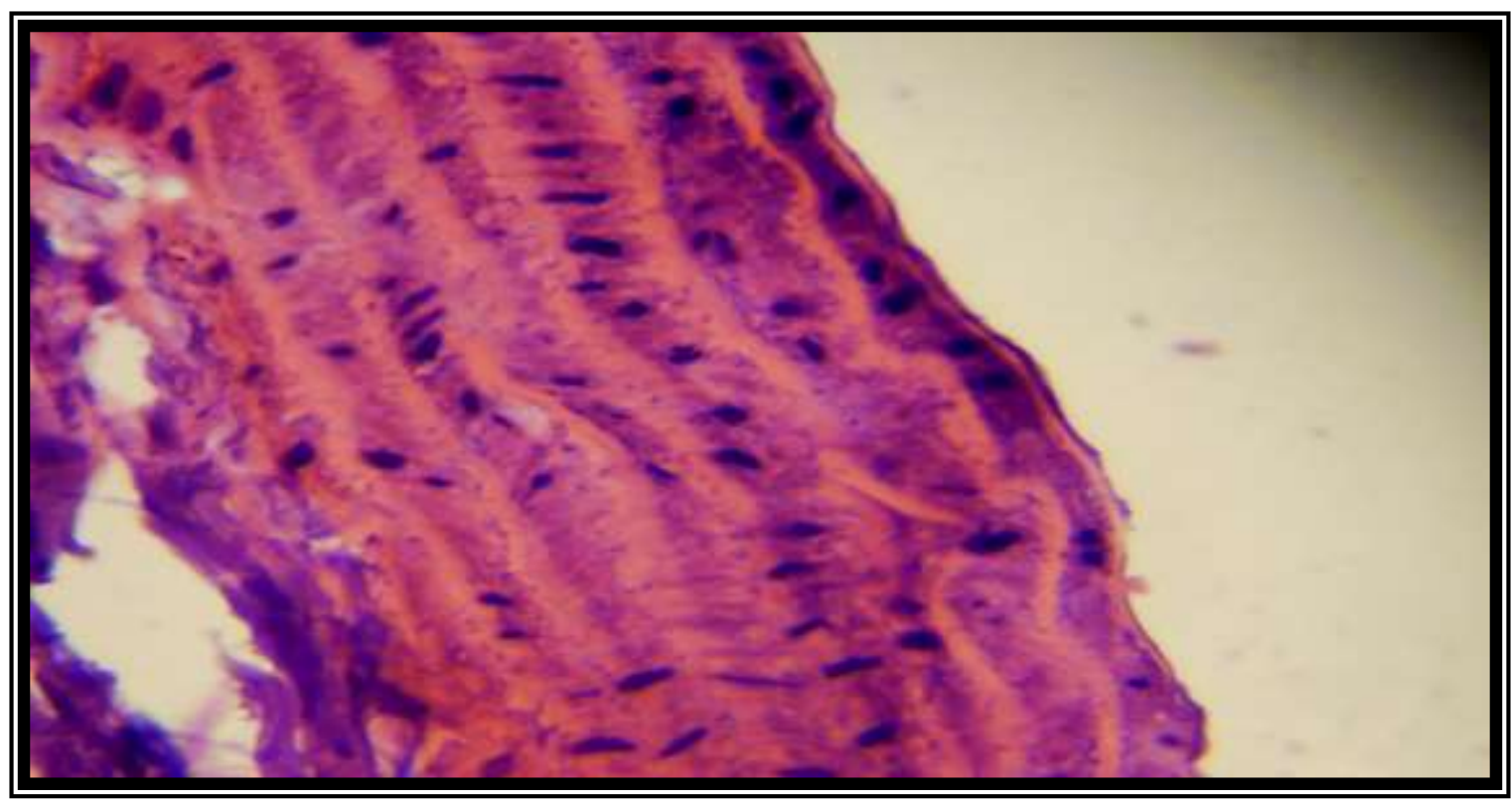

Figure (11) Histological section of aorta treated $\mathrm{H} 2 \mathrm{O2}$ Plus black currant concentrate complete regression of lesion in layer of its. H.E 40X. 


\section{Discussion}

The currant study demonstrated that oral intubation of $0.5 \% \mathrm{H} 2 \mathrm{O} 2$ in drinking water for six weeks to adult male rats caused significant damage to cardiovascular system. The damaging effects of hydrogen peroxide on cardiovascular system were observed in all diagnostic markers examined in relation to 1- Prothrombin time, 2- platelet count, 3- serum lipid profile, 4histological section of hearts and aorta. Beside oral intubation of black currant concentrate or vitamin E concurrently with $\mathrm{H} 2 \mathrm{O} 2$ exerted significant cardioprotection against $\mathrm{H} 2 \mathrm{O} 2$ induced oxidative damage in all end points examined.

Enhancement of lipid peroxidation \& analysis of lipid membrane on platelet surface with enhancement of Coagulation factors (Thrombin and Thromboxane A2) by $\mathrm{H} 2 \mathrm{O} 2$ exposure has been reported (18). On other hand $\mathrm{H} 2 \mathrm{O} 2$ exposure enhanced transferring of fibrinogen to fibrin, thrombocytosis with subsequent suppression of prothrombin time $(19,20)$.

The result of the present study revealed a case of hypercholesterolemia following $\mathrm{H} 2 \mathrm{O} 2$ intubation which may be considered in the resultant thrombocystosis. Beside oxidized LDL are more reactive than native LDL in this issue (21). So we can postulate that oxidation of LDL by $\mathrm{H} 2 \mathrm{O} 2$ contribute greatly. Vitamin $\mathrm{E}$ has been recorded to be known inhibitor of platelet aggregation and these effects appears to be dose dependent (22).Supplementation of antioxidant; vitamins including vitamin E caused inhibition of platelet activation (23). And this effect might be due to its antioxidant and cardioprotective action (24). Our results demonstrated that oral intubation of aqueous extract of black currant concentrate significantly depressed thrombocyte number with elevation of prothrombin time (tables 1,2). Black currant concentrate have been shown to possess antioxidant activity by way of $\mathrm{H} 2 \mathrm{O} 2$ scavenging capacity, lowering lipid peroxidation with subsequent correction the depressed prothrombin time \& thrombocytosis induced by $\mathrm{H} 2 \mathrm{O} 2$ (25). Both vitamin $\mathrm{C}$ concentration and total phenolic content of black currant strongly correlates with its antiplatelet effect $(26,27)$. Partial diffiency of lipoprotein lipase (the key enzyme determining the removal rate of TG from plasma), associated with increased output of lipoprotein from the liver may contribute to the elevation of serum TG level in $\mathrm{H} 2 \mathrm{O} 2$ treated group (28). The present study showed that oral intubation of vitamin E plus $\mathrm{H} 2 \mathrm{O} 2$ in drinking water caused positive changes in serum lipid profile through significant decline in the mean value of serum TC, TAG, LDL-C and VLDL-C concentration \& elevation in serum HDL-C concentration in comparison to control group (tables $3,4,5,6,7)$.This result insures the hypolipidemmic and the corresponding cardioprotective effect of vitamin E.A significant body of literature correlates dietary vitamin E supplementation with regression of cardiovascular incidence 
and mortality $(29,30)$. The cardioprotective effects of vitamin $\mathrm{E}$ are attributed to its antioxidant properties. Vitamin $\mathrm{E}$ is able to extinguish single oxygen species as well as to terminate free radical chain reactions (31).

Oral administration of black currant concentrate to adult rat for six weeks exerted hypocholesterolemic effect (depression of serum TC, LDL-C concentration) and hypotriglyceridemic effect. Mean while serum HDL-C concentration was significantly increased following black currant intubation (tables 3, 4, 5, 6). These results were in agreement with the result of other workers in which different currant species, experimental duration and different age were used in healthy and hemodialysis patients $(32,33)$. As reviewed by Particia Castilla and his colleagues (33), supplementation of red grape juice causes significant decline in LDL-C\& apolipoprotein-B concentration with elevation of HDL-C \& Apolipoprotein -A concentration in hemodilysis patient subject. Several active ingredients in black currant (seed, skin\& concentrate and juices) may attributed to the hypolipidemic effect of the currant: 1- First at all black currant (seed, skin and concentrated juice ) are regarded as food soures of phytochemicals such as catechin, epicatechin, the known hypolipidemic effect of the currant(34), 2-Besides antioxidant compound present in black currant (PCO) might have ability to directly (scavenge $\mathrm{OH}^{*}$ ) protect LDL from oxidation and reduces serum cholesterol level $(25,35)$ and improving the lipoprotein profile through decreasing the LDL-C concentration (33), 3-Another investigator postulated that vitamin $\mathrm{C}$ content could be considered the major contributor to the antioxidant capacity \& the corresponding hypolipidemic effect of black currant (36). (Figures 3, 4, 5, 6, 7, 8, 9), indicating occurrence of oxidative stress by $\mathrm{H} 2 \mathrm{O} 2$ leading to athermatous lesions. The functional role of oxidative stress induced by free radicals including (Hydrogen peroxide) in endothelial dysfunction and the resultant atheroma was reported $(37,38)$. The histological examination of aortic, pulmonary and cardiac muscle of rat received aqueous extract of black currant concentrate revealed complete regression of cardiac damage and athermatous lesion caused by $\mathrm{H} 2 \mathrm{O} 2$ (Figures $10,11)$. Research also suggested that antioxidant found in grape juice may act to promote healthy cardiovascular function through protection of LDL from risk of free radical which leads to minimize interaction of ROS \& bad cholesterol, help to keep arteries clear and reduce stickness of blood (39). Besides, reversterol posses cardiomyocyte protection against oxidative stress lessens occurance of foamy cells \& prevent blood cell adherence). Black currant has been repoted to contain considerable amount of vitamin $\mathrm{C}$ and reverosterol which may contribute to it antiatherosclerotic effect. (40). On conclusion, it appears that different antioxidant \& active ingredients of black currant contribute to it cardioprotection effect. And it seems that inspite of antiatheroscleratic effect of vitamin $\mathrm{E}(29,41)$. Vitamin $\mathrm{E}$ failed to counteract the damaging effect of 
$\mathrm{H} 2 \mathrm{O} 2$.This may be attributed to differences in duration of the experiment and the prolonged action of $\mathrm{H} 2 \mathrm{O} 2$.

\section{References}

1- Sharma, G.; Tyagi, Ak.; Singh, RP.; Chan, DC.; and Agarwal, R. (2004).Synergistic anti-cancer effect of grape seed extract and conventional cytotoxic agent doxorubicin against human breast carcinoma cells. Breast Cancer Research and Treatment. 85(1):1-12.

2- Hedrick,U.P.(1925).The small fruits of New York.J. B.Lyon. Co .Alban,N.Y.

3- Kim, E. Hummer and Danny, Barney, L. (2002). Crop Reports.

4- Erlund, I .;Marniemi, J .; Hakala, P .; Alfthan, G.; Meririnne, E .; and Aro, A.(2003). Consumption of black currants, lingon berries and bil berries increases serum quercetin concentrations. Eur J Clin Nutr; 57:37-42.

5- Ehala, S .,Vaher, M .; and Kaljurand, M .(2005). Characterization of phenolic profiles of Northern European berries by capillary electrophoresis and determination of their antioxidant activity. J Agric Food Chem .53:6484-6490.

6- Rechner, AR .; Kuhnle, G .; Hu, H.; et al.(2002). The metabolism of dietary polyphenols and the relevance to circulating levels of conjugated metabolites. Free Radic Res .;36:1229-1241.

7- Maatta, K .; Kamal-Eldin, A.; and Torronen, R. (2003). Phenolic compounds in berries of black, red, green, and white currants (Ribes sp.). Antioxid Redox Signal; 3:981-993.

8- Wu, X.; Gu, L.; Prior, RL.; and McKay, S. (2004). Characterization of anthocyanins and proanthocyanidins in some cultivars of Ribes, Aronia, and Sambucus and their antioxidant capacity. J Agric Food Chem; 52:7846-7856.

9- Shao, Zh.; Vanden Hoek TL, Li CQ, et al (2004). Synergistic effect of Scutellaria baicalensis and grape seed proanthocyanidins on scavenging reactive oxygen species in vitro .American Journal of Chinese Medicine.32 (1):89-95.

10-Whitley,AC.;Sweet,DH.;andWalle,T.(2006).Site-specific accumulation of the cancer preventive dietary polyphenol ellagic acid in epithelial cells of the aerodigestive tract Pharma Pharmacol.58(9).1201-1209.

11- Eng,ET. ;Ye,J. ;Williams,D.; Phung,S.; Moore,RE. Young, Mk.et al. (2003) Suppression of estrogen biosynthesis procyanidin dimmers in red wine and grape seeds. Cancer Res.63 (23):8516-8522.

12- Shi, J.; Yu, J.; pophorly, JE; and KaKuda, Y. (2003). Polyphenolic in grape seedsbiochemistry and functionality. Journal of Medicinal Foods.50 (21):6217-6221.

13-Yuko,Nakamural.;Hitoshi,Matsumotol.andKazuo,Todoki.(2002).Endoth-

Dependent vasorelaxation induced by Black currant concentrate in rat thoracic aorta.Jpn.J.Pharmacology.89, 29-35. 
14- Sheweita, SA.; Abd, El-Gabar, M, and, Bastawy, M. (2001).Carbon tetrachloride induced changes in the activity of phase $\Pi$ drug metabolizing enzymes. Toxicology. 165:217-224.

15-Archer,R.K.(1965).Haematological techniques for use on animals. black well scientific publication oxford. Public Health pp:37-44.

16- Friedewald ,W.T.;levy ,R.I.;and Fredrickson ,D.S.(1972).Estimation of the Concentration of low -density lipoprotein cholesterol in plasma without use of Preparative ultracentrifuge.Clin chem ,18:499-502 .

17- Snedeccor, G.W and Cochran, W.G. (1973).Statistical methods. $6^{\text {th }}$.the Iowa State university pres .pp:238-248.

18- Ganong, W. F. (2005). Review of medical Physiology. $22^{\text {nd }}$ ed. Lange Medical Books / McGraw - Hill Boston, Toronto, New Jersey, pp: 424 - 430.

19- Neals, S.D. (1999). About of thrombin .American heart journal. 137: 196-199.

20- James, C.F., and Beltrame J. (2002). Effect of vit C \& E on progression of transplant - associated atherosclerosis: randomized trial Lancet: 359: 1108-1113.

21- Ardlie ,N.G.; Salley,M.L.and Simons,L.A.(1989).Platelet activation by oxidatively modified low density lipoproteins Atherosclerosis ,76:117-124.

22-Turkdo ,M.K;An,Z.A.;Yener,Z.and sekero, R.(2001). The role of antioxidant vitamins (C\&E), Selenium on liver cirrhosis and fibrosis in rabbits: Br-J-Nutr. 81(6):425-426.

23-Mabile,L.;Bruckdorfer, KR.; and Rice-Evans, C. (1999).Moderate supplementation with natural alpha-tocopherol decreases platelet aggregation and low-density lipoprotein oxidation. Atherosclerosis; 147:177.

24- Meagher, EA. Barry, OP.; Lawson, JA. et al. (2001). Effects of vitamin E on lipid peroxidation in healthy persons. JAMA; 285:1178.

25- Pinelo, M.; Landobo, Ak.; Vkbjerg, Af.; and Meyer, AS.(2006). Effect of clarification techniques and rat intestinal extract incubation on phenolic composition and antioxidant activity of black currant juice. J Agri Food Chem. 6; 54(18): 6564-6571.

26- Prior, R. L. (2003). Fruits and vegetables in the prevention of cellular oxidative damage. American Journal of Clinical Nutrition, 3: $570 \mathrm{~S}-578$.

27- Shafiee, M.; Carbonneaum, A.; Urban, n.; DEscomps, B. and Leger CL. (2003).Grape and grape seed extract capacities at protecting LDL against oxidation generated by $\mathrm{CU} 2+$, AAPH orSIN-1 and at decreasing superoxide thp-1cell production .A comparison to other extracts or compounds. Free radical Research. 37 (5):573-584.

28- Fantiappie, U.; Helmius, G.; Hemmingsson, A.; Ruhn, G. and Olsson, A.G. (1989). Repeat femoral arteriograph in hyperlipidemic patients, a study of progression and regression of atherosclerosis. Acta Radiol., 29(3): 303-309.

29- Pryor, W. (2000). Vitamin E and heart disease: Basic science to clinical intervention trials. Free Radic Biol Med; 28(1):141-64. 
30- Iuliano „L.; Micheletta, F.; Maranghi, M.; Frati G.; Diczfalusy U.; and Violi, F. (2001). "Bioavailability of Vitamin E as Function of Food intake in Healthy Subjects". Arteriosclerosis, Thrombosis, and Vascular Biology 21: 34-37. 31-Giugliano, D. (2000). Dietary antioxidants for cardiovascular prevention. Nutr Metab Cardiovasc Dis; 10(1):38-44.111.

32- Zern, TL.; Wood, RJ.; Greene, C.;West, KL.; Liu, Y. Aggarwal, D.; Shachter, NS. and Fernandez, ML.(2005). Grape polyphenols exert a cardioprotctive effect in pre-and postmenopausal women by lowering plasma lipids and reducing oxidative stress. J Nutr, 135(8): 1911-1917.

33 Patricia, Castilla.; Rocio, Echarri.; Alberto, Davalos.; Francisca, Cerrato.; Henar, Ortega.; Jose, Luis.; Teruel, Milagros.; Fernandez, Lucas.; Diego, Gomez-.; Coronado, Joaquin, Ortuno. and Miguel Al Lasuncion.(2006).concentrated red grapejuice exert antioxidant, hypolipidemic and antinflammatory effect in both hemodialysis patient and healthy subject.american Journal of clinical nutritional 84(1)252:262.

34- Yilmaz, Y.; and Toledo, RT. (2004). Major flavanoids in grape seeds and skins: antioxidant capacity of catechin, epicatechin, and gallic acid. J Agri Food Chem. 28; 52(2):255-260.

35- Vibeke, M.; Breinholt, Salka E.; Nielsen, Pia.; Knuthsen, Soren T .Lauridsen, Bahram Daneshvar, and Annemarie Sorensen .(2003). Effect of commonly consumed fruit juices and carbohydrates on redox status and anticancer biomarkers in female rats. Nutr. Cancer 45(1) 46-52.

36- Rho KA, Kim MK .(2006).Effects of different grape formations on antioxidative capacity, lipid peroxidation and oxidative DNA damage in aged rats Nutr Sci Vitaminol (Tokyo) 52(1): 33-46.

37- Wolkart, G.; Kaber, G.; Kajda, G.; and Brunner, F.(2006). Role of endogenous hydrogen peroxide in cardiovascular ischaemia/reperfusion function: Stuies in mouse hearts with catalase overexpression in the vascular endothelium. J. Biophys. Res. 8: 245 - 251.

38- Yasunori Kokusho; Tatsuya Komaru; Satoru Takeda; Katsuaki Takahashi; Ryoji Koshida; Kunio Shirato; and Hiroaki Shimokawa.(2007).Hydrogen Peroxide Derived From Beating Heart Mediates Coronary Microvascular Dilation During Tachycardia Arteriosclerosis, Thrombosis, and Vascular Biology; 27:1057.

39- Danny E.C.van Hoorn, Robert J, Nijveldt, Petra G.Boeleus. Zandrie Hofman, Paul A.M. van Leeuwen, and Klaske van Norren(2006).Effect of preoperative flavonoid supplementation on differentorgan functions in rats .Journal of parenteral and Enteral Nutrition, 30,(4):302-308.

40- Cao,Z.and Li,Y.(2004).Potent induction of cellular antioxidants and Phase2 enzymes by resveratrol in cardiomycytes: protection against oxidative and electrophilic injury .European Journal of pharmacology .489(1-2):39-48. 
Iraqi Journal of Veterinary Medicine Vol. 32, No. 2, 2008

41- Vogel, R. (1999). Cholesterol lowering and endothelial function. Am J Med; 07(5):479-87. 